\title{
WestVirginiaUniversity
}

THE RESEARCH REPOSITORY @ WVU

Graduate Theses, Dissertations, and Problem Reports

2021

\section{Analyzing Safety Audits to Improve Logging Safety Performance}

\author{
George Daniel Nolan jr \\ West Virginia State University, gdn0001@mix.wvu.edu
}

Follow this and additional works at: https://researchrepository.wvu.edu/etd

Part of the Other Forestry and Forest Sciences Commons

\section{Recommended Citation}

Nolan, George Daniel jr, "Analyzing Safety Audits to Improve Logging Safety Performance" (2021). Graduate Theses, Dissertations, and Problem Reports. 10339.

https://researchrepository.wvu.edu/etd/10339

This Thesis is protected by copyright and/or related rights. It has been brought to you by the The Research Repository @ WVU with permission from the rights-holder(s). You are free to use this Thesis in any way that is permitted by the copyright and related rights legislation that applies to your use. For other uses you must obtain permission from the rights-holder(s) directly, unless additional rights are indicated by a Creative Commons license in the record and/ or on the work itself. This Thesis has been accepted for inclusion in WVU Graduate Theses, Dissertations, and Problem Reports collection by an authorized administrator of The Research Repository @ WVU. For more information, please contact researchrepository@mail.wvu.edu. 


\title{
Analyzing Safety Audits to Improve Logging Safety Performance
}

\author{
George D. Nolan Jr. \\ West Virginia University Division of Forestry \& Natural Resources, \\ Appalachian Hardwood Center
}
Thesis submitted to the Davis College of Agriculture, Natural Resources, and Design at West Virginia University

in partial fulfillment of the requirements for the degree of

\author{
Master of Sciences \\ In \\ Forestry \\ Committee Members: \\ Joe McNeel, Ph.D. Co-Chair \\ Curt Hassler, Ph.D. Co-Chair \\ Ben Spong, Ph.D. \\ Ida Holásková, Ph.D.
}

Division of Forestry and Natural Resources

Morgantown, West Virginia

2021

Keywords: Safety Audits, Logging Safety Inspections

Copyright 2021 George Nolan 


\title{
Abstract \\ Analyzing Safety Audits to Improve Logging Safety Performance
}

\author{
George Nolan
}

This study examines logging safety audits to determine how different variables, and differing amounts of time between audits, affect the outcome of safety score performance. To collect the data for this study a three-page paper audit was used that examined five areas of the logging site which include: Personal protective equipment (PPE), general, felling, mobile equipment and, landing and loading.

The study analyzed 3 aspects of the audit which were the total score and the subcategories of PPE and felling since they were the two heaviest weighted sections. The analysis only included audits that had a 5 percent or greater drop in score from the previous audit. Having at least 5 percent drop does not mean that a company had a failing safety score but does indicate that they are regressing. Three linear mixed models were developed, one each for total, PPE and felling score using the days in compliance per audit as the response variable. Number of personnel and season (warm/cold) were the fixed effects and the entity, as a surrogate for the logging company, was used as a random variable in models.

Predicted values of normalized days in compliance were calculated for each of the models with 2 through 10 personnel in both warm and cold seasons and organized into tables. They indicate number of days between the audits before the scores may decrease at least 5 percent of previous score. The PPE had the widest range of days in compliance per audit from 92 thru 154 days. The felling model had lowest range of days in compliance per audit from 86 thru 132 days depending on the input. PPE had the steepest slope of all the models.

Continued research should be completed with possibly pairing audit data with worker compensation claims or injury reports to examine the potential auditing on preventing accidents. 


\section{Acknowledgements}

I would like to express my deepest appreciation to my committee. Without this team I would not have made it to completion: co-chairs Dr. Joe McNeel and Dr. Curt Hassler, committee member and statistician Dr. Ida Holásková, and committee member Dr. Ben Spong. Without their support, dedication, and determination, this study would still be on going. So, a great big thanks and debt of gratitude go to this committee.

Also, I would like to thank Curt Hassler, Tim Pahl, the West Virginia Forestry Association Loggers Safety Initiative (WVLSI), and the Mountain Loggers Group Safety Initiative (MLGSI). Thank you for your dedication to logging safety and generosity for collecting and donating the data used in this research. Without it, I would not have been able to complete my degree, so thank you and God bless.

Lastly, I would express my gratitude to Matt Walker, statistician assistant for Dr. Holásková, for his dedication in analyzing the data. 


\section{Table of Contents}

Analyzing Safety Audits to Improve Logging Safety Performance .........................................iii

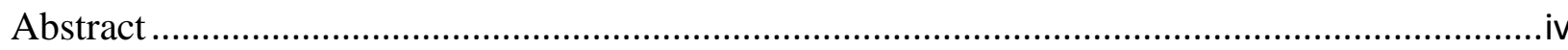

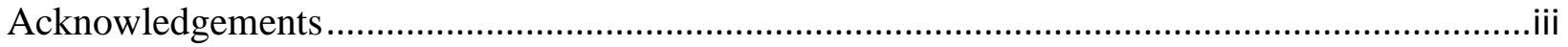

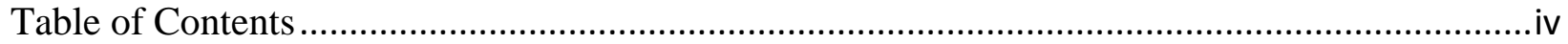

Table of Contents of Tables ......................................................................................................

Table of Contents of Figures ....................................................................................

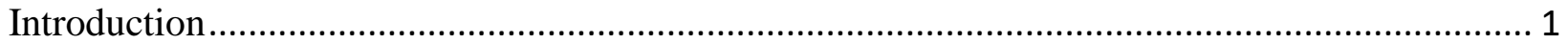

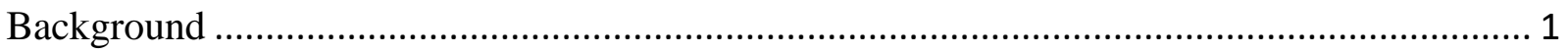

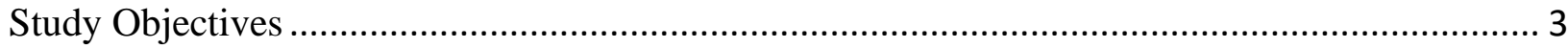

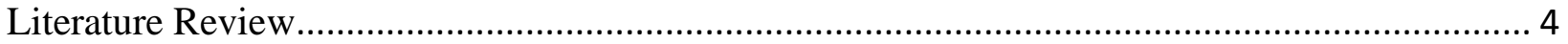

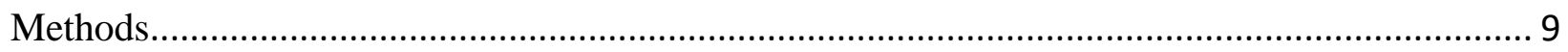

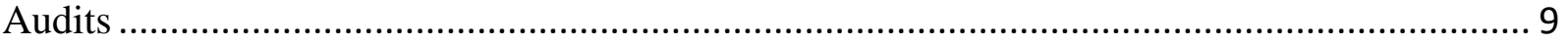

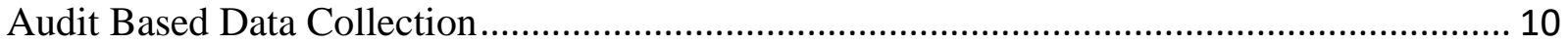

Sample Size, Data Filtering, and Pre-processing ........................................................ 14

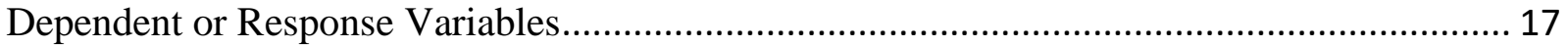

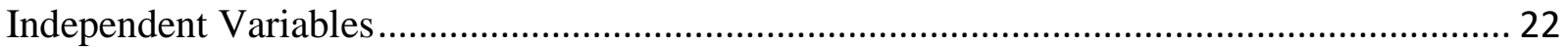

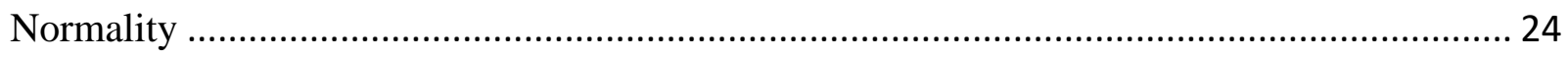

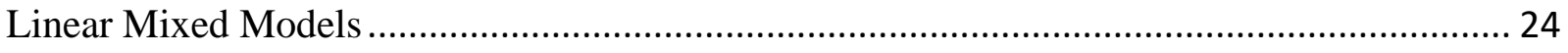

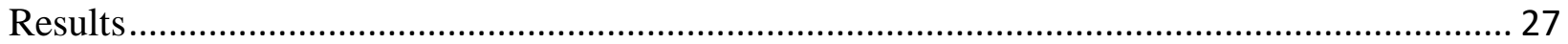

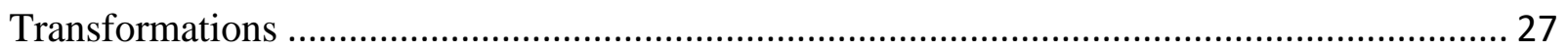

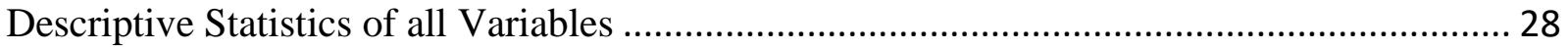

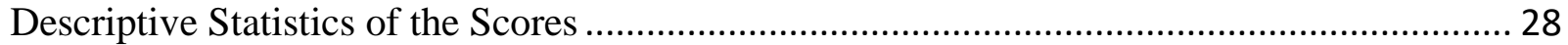

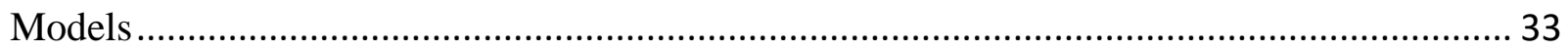

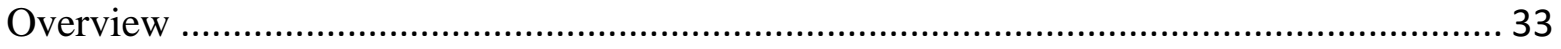

Days in Compliance per Audit Total - Model 1 ........................................................... 36

Days in Compliance per Audit PPE - Model 2 .......................................................... 38

Days in Compliance per Audit Felling - Model 3 ............................................................. 40

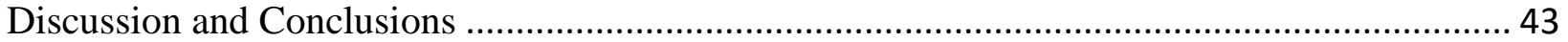




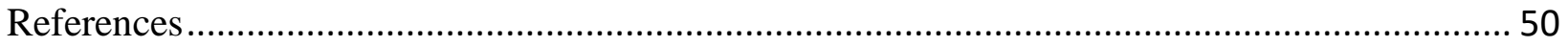

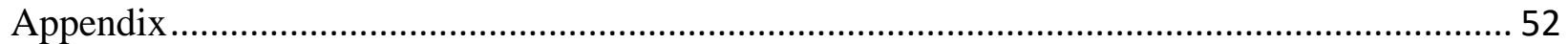

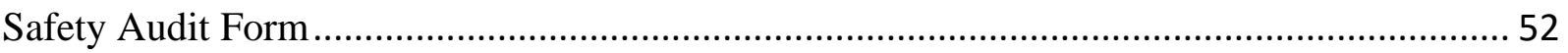




\section{Table of Contents of Tables}

Table 1. Example of the division of companies into Entities regarding the "no more than 365 days in between audits" criteria

Table 2. Example of derivation of variables "Days in Compliance for Total score", "No. of Audits from start or Recurrence" or Days in Compliance per Audit", using Entity_1 as an example.

Table 3. Distributions of the untransformed and transformed dependent variables for only audits that had at least a five percent decrease in scores ( $\mathrm{N}=106$ audits), using Shapiro-Wilk W test. The p-values are included above the graphs.

Table 4. Descriptive statistics of the original and modified data sets that are included in the linear mixed model analysis. The continuous variables are represented as the mean $\pm \mathrm{SE}$, (range) and categorical variables are listed as counts (percentages).

Table 5. Descriptive statistics for the audits scores that include the Total Score and subcategories of PPE Score and Felling Score. N = 547

Table 6. Descriptive statistics of the audits that exhibited at lest 5 percent drop in score from the previous audit. The continuous variables are represented as the mean \pm SE (range) and categorical variables are listed as counts (percentages).

Table 7. Full models at the beginning stages of the analysis. Each coefficient is listed first followed by the corresponding p-value for that effect. Entries in bold are significant p-values. . 34 Table 8. Final models used in the analysis that only examine Audits where a drop of 5 percent or more in score was observed. The coefficient is listed first, then the p-value. Significant p-values are in bold.

Table 9. Estimates of Days in Compliance per Audit Total according to changes in Personnel and Season 2 from Model 1.

Table 10. Estimates of Days in Compliance per Audit for PPE Score according to changes in Personnel and Season 2 from Model 2.

Table 11. Estimates of Days in Compliance per Audit for Felling Score according to changes in Personnel and Season 2, based on Model 3. 


\section{Table of Contents of Figures}

Figure 1. Flow chart of progression of the data modification/preparation before the statistical analysis..... 16

Figure 2. Flow chart presenting how the final database was developed, based on Audit scores that decreased by at least 5 percent from the previous Audit for Total Score, PPE Score, and Felling Score.

Figure 3. Bar graph of Days in Compliance per Audit for Total Score estimates with changes in Personnel in Season 2 warm and cold. The figure depicts 2 through 10 Personnel but the model can be used to estimate up to 14 Personnel's Days in Compliance per Audit.

Figure 4. Bar graph of Days in Compliance per Audit for PPE Score estimates with changing Personnel in the warm and cold Season. The figure depicts 2 through 10 Personnel but the model can be used to estimate up to 13 Personnel's Days in Compliance per Audit.

Figure 5. Bar graph of Days in Compliance per Audit for Felling Score estimates when changing Personnel in Season 2 warm and cold. The figure depicts 2 through 10 Personnel but the model can be used to estimate up to 13 Personnel's Days in Compliance per Audit.

Figure 6. Trendlines of all three models Days in Compliance per Audit show casing the intersection between Total and PPE in the warm Season.

Figure 7. Trendlines of all three models Days in Compliance per Audit show casing the intersection between Total and PPE in the cold Season. 


\section{Introduction}

\section{Background}

Logging is often cited as one of the most hazardous occupations in the US by the Bureau of Labor Statistics (BLS), due to the harsh work conditions, number of injuries, and fatalities that occur annually. The BLS also determined that logging consistently produces a high percentage of injuries and fatalities compared to other occupations in the US (BLS, 2004). Janocha and Hopler (2018) analyzed data from the Census of Fatal Occupational Injuries for the period between 2006 and 2015 and found that there were 8,380 non-fatal injuries in private industry during that period. Based on their analysis, in 2015 the non-fatal injury rate in the logging industry was 133.2 per 10,000 full-time equivalent workers. They concluded that the work-related injury rate for logging was about 40 percent higher than the average industry rate of 93.9 per 10,000 workers.

Unlike many other occupations, logging occurs in an environment where the hazards are numerous and variable. Hazardous conditions change on a frequent basis as logging crew members move around the logging site. Weather and terrain both contribute significantly to the ever changing and common occurrence of hazards encountered. On any given day, a logger can face harsh weather conditions that could include excessively wet and muddy conditions, freezing/icy conditions in winter circumstances, high winds, or extreme heat during the summer months. Steep slopes common to West Virginia and the Appalachian Mountains also create conditions that make it difficult to fell, limb and buck, and skid trees to a log landing.

At its core, the perception of logging as a dangerous occupation is based on the frequency of hazards encountered by a logger. Adopting an attitude that a safety hazard is simply an unsafe 
condition or behavior that could lead to an injury, the path to minimizing accidents is clear. If a hazard has been identified and controls are in place to protect the employee from that hazard, no danger need exist. Even when a hazard must be dealt with, for example a danger tree (which is a tree that has been cut and gets hung up in a neighboring tree or an old dead snag that has the potential for injuring someone), there are usually sound, safe, and timely procedures for dealing with that hazard.

According to Garland et. al (2019), for an accident to happen, at least two conditions must exist; first, there must be a hazard present that could potentially contact a worker and second, there must be work being done in proximity to the hazard. Therefore, if loggers can recognize a hazard in advance, the hazard can be avoided or mitigated. The two primary ways to minimize accidents and injuries on a logging job are first, proper training relative to possible hazards that could be encountered and knowing how to mitigate those hazards. Second, through the use of frequent safety audits to reinforce the importance of hazard recognition and mitigation. Properly trained/experienced employees who are confident in their knowledge of existing hazards and the potential dangers that could occur without safety controls constitute the front line in workplace safety.

The presence of hazards at any given logging site, particularly those where manual or partially mechanized logging systems are used, is much higher than at other industrial sites. Safety audits (audit and inspection are used interchangeably here) could potentially play an important role in helping to mitigate some of the many hazards' loggers experience every day in the forest. Loggers could routinely use these safety audits to identify and mitigate recurring hazards that could eventually harm an employee. For example, failure to use appropriate 
Personal Protective Equipment (PPE) would show up on an audit and could be remedied before the next inspection and perhaps prevent an injury.

Safety audits can play an important role for insurance companies and their logger clients. These audits provide a way for insurance companies to determine a logging operations safety ethic and adjust their rates to fit. It is unknown if all insurance agencies use this method, but it could be potentially helpful. If insurance providers could predict the optimal time period between inspections, the insurance companies would spend less on administrative costs and the logger could be subjected to fewer of these inspections over time. But this approach would only work if the inspection process yielded consistent or improved safety performance from the logging crew following the audits.

\section{Study Objectives}

The primary objective of this study is to determine how logging company safety performance changes, based on recorded safety audit scores, with differing periods of time between safety audits, and what variables influence these changes. The second objective is to determine the optimal length of time between safety audits that will maintain audit scores at an acceptable level and, by inference, reduce the incidence of accidents and injuries. Little, if any, research has been conducted comparing periodic safety audits for individual companies, so the overall intent of this study is to provide insight into this approach for maintaining logging site safety. 


\section{Literature Review}

Logging operations recorded 655 fatal accidents from 2006 to 2015, making it one of the most dangerous occupations in the US. In 2015, the fatal injury rate was 132.7 per 100,000 full time employees (FTE), nearly forty percent higher than the national average of 3.4 per 100,000 FTE (Janocha and Hopler, 2018). The logging industry had the highest five-year annual fatality rate in the years 1992 through 1996, with 112 fatalities per 100,000 employees (Myers et al.,1998). Fosbroke et. al (1997) estimated that, over a 45-year period, 62.7 people out of 1000 would die from an occupational injury in the timber felling/logging occupational category under existing conditions.

Non-mechanized or manual logging configurations are more hazardous than mechanized operations, primarily because more employees are working without the protection of an equipment cab. Fellers in a manual operation use a chainsaw to fell the trees that puts them in the danger zone. Where mechanized operators are in a machine that has a boom with a cutting head attached that grabs the tree and cuts it without having to get out of the cab, this makes for a much safer work environment. In fact, a study by Bell and Helmkamp, that examined workers compensation (WC) claims from 1995 to 2001 for non-fatal injuries for the entire logging industry of W.V., found that almost half (47\%) of all claims were listed as struck by. A similar study by Bonauto et. al. (2019) for Washington state using WC claims for 2005 thru 2014 found that 54 percent of reported claims were stuck by injuries. They also found that non-mechanized operations had a claims rate of 46.6 per 100 FTE while mechanized operations had a claim rate of 6.7 per 100 FTE. So, this means that being inside a cab would mitigate these hazards, also when using a feller-buncher the operator can maintain more of a safe distance from the falling tree unlike the chainsaw operator. Loggers working in a non-mechanized system directly 
confront the changing environment and climate, on the other hand, loggers using a mechanized system have heated cabs, rollover protection (ROPS) and falling object protection (FOPS). They also have bullet-proof wind shields among other safeties.

In fact, a review of logging fatalities in WV from 2000 thru 2020, using inspection data taken from the OSHA website, that only inspection types categorized as "accident" "fatality/casualty" were included in the analysis. It suggests that over 80 percent of the fatalities that occurred on non-mechanized logging operations involved a chainsaw. Of 53 total OSHA reports, 49 of them reported fatalities, with recorded accident details. Of these, 39 reported that a chainsaw was involved in the fatality (OSHA, 2020). There were four listings that did not provide any description and therefore were not used. These data were obtained from the www.osha.gov website through a search based on West Virginia, and the codes SIC -2411 for 2000 through 2006 and NAICS code - 113310 for 2007 through 2020.

The Texas A\&M Farm Safety Program states that there were over 28,500 chainsaw injuries (these injuries were not all logging related) in 1999 based on analysis of Consumer Products Safety Commission data (Smith,1999). The author also notes that the average reported injury required 110 stiches to close the wound.

A study conducted by Bell (2002) for the Centers for Disease Control and Prevention's National Institute for Occupational Safety and Health (NIOSH) examined the differences in injury claim rates between mechanized and non-mechanized loggers in West Virginia over a sixyear period $(1995-2000)$. She evaluated eleven logging companies that switched from manual chainsaw felling to the use of a feller-buncher for felling and examined the injury claim rate over a period of about two and a half years before and two years after the transition to mechanized systems. The study suggested that a significant drop in the injury claim rate occurred - from 19.4 
per 100 workers to 5.2 per 100 workers over the transition period. This study generally illustrated that mechanical harvesting was safer for workers. However, the study also concluded that feller-bunchers have limited potential in Appalachia because of the steep terrain. Thus, loggers must still use chainsaws on many sites for felling operations.

Unfortunately, in mountainous terrain, such as the Appalachians, it is often not possible to deploy fully mechanized logging configurations, which result in a greater frequency and severity of hazards are much greater. However, with advancements in technology, loggers are becoming more capable of harvesting these more difficult sites with machines, rather than use chainsaws for the felling. A study for NIOSH conducted by Oregon State University examined ways to improve safety when logging on steep slopes. The study concluded there were significant safety related differences between traditional logging techniques and new technologies for logging steep slopes. The study also determined that, with new technology, “...there was a reduction in exposure to hazards and a reduction to workers exposed to the most serious (hazardous) work in logging operation on steep slopes" (Garland, et al, 2019). Some of these new technologies include tethering excavator type machines down steep slopes with computer-controlled winches and computer-controlled grapples on yarders that reduce the need for on the ground workers.

A program was initiated in West Virginia (WV) in 1999 to examine the effectiveness of logger safety training programs for WV logging companies participating in a safety program called the WV Loggers Safety Initiative (LSI). The LSI program was a safety driven project that ran continuously over a four-year period from 1999 to 2003 and intermittently for the next three years until 2006. The program was designed to promote safety training combined with periodic inspections/audits. Participating loggers received up to 15 percent reductions on worker 
compensation insurance rates combined with specialized training for all employees. Bell and Grushecky (2006) completed a study to determine the efficiency of the LSI program, by comparing workers compensation (WC) claim rates. Claims rate is the number of claims a company has filed within a certain period of time. For the study WC claim rates of WV logging companies that participated in the LSI program were compared to the WC claim rates of WV logging companies that did not participate. There was no statistically significant evidence to suggest that the companies participating in LSI had lower WC claim rates than those that did not participate. In fact, both cohorts had a claims rate of 16.23 per 100 FTE. However, they did find that there were factors associated with claim rate differences.

Among the companies in the LSI program those that used a feller-buncher, at least part of the time, had a claim rate less than half of those that had a manual operation. This supports a study mentioned earlier by Bell (2002) that mechanized operations have lower claim rates. Bell and Grushecky (2006) found that as the number of inspections received increased, there was a decrease in claim rates and there were even lower claim rates for those companies that participated the whole time the LSI program was implemented. Also, the researchers calculated the average annual turnover rate for the duration each of the companies participated in the LSI program and found that high turnover rate was positively correlated with higher claim rates. (Bell and Grushecky, 2006).

Research completed by Helmkamp et. al (2004) observed how effective a safety video on safety was on employee awareness of safety issues. The researchers presented a specially prepared safety video to West Virginia loggers from April of 2002 through October 2003. This video was shown during logger training conducted by the West Virginia Division of Forestry (WVDOF). A pre-survey was given to loggers about to view the video to test their knowledge of 
safety. After showing the video, loggers who viewed it were given a post-survey to complete. This was followed up by phone calls six months after the viewing and finally, field guides were provided to the loggers to reinforce the points in the video. Responses to 10 out of the 13 questions covered in the video showed statistically significant improvement. The authors concluded that, "It was quite apparent that the video strongly influenced the loggers and improved their knowledge about the primary hazards in logging and ways to mitigate these hazards" (Helmkamp et. al, 2004).

Several safety programs have been implemented to help loggers work safer, including Logging E-tool, an OSHA developed website that covers most everything a logger needs to know about safe work in logging over the range of logging equipment configurations; Game of Logging $®$, which focuses mainly on chainsaw safety and teaches fellers how to fell trees the safest way through hands-on training; and the LSI, which is explained above. However, very few of these programs, if any, have used safety audits to single out the hazards experienced on the jobsite. OSHA conducts safety inspections periodically, although these can be punitive inspections where citations are made for OHSA standards violations. Often, the citations are not tied to hazard related problems, but have more to do with paperwork required for OSHA reporting. For example, from 2009 to 2015, West Virginia had 74 planned inspections by OSHA with a total of 374 citations generated. Of those citations, only 77 were hazard related, an additional 62 were PPE related violations, and the rest, 237 violations (63 percent) were nonhazardous citations (OSHA, 2020).

In summary, there are many safety tools in place to help mitigate hazards but there is still work to be done, particularly in the Appalachian area. This study attempts to address these issues. 


\section{Methods}

\section{Audits}

Safety audit data used for this project were obtained from two sources, the West Virginia Forestry Association Loggers Safety Initiative (WVLSI) and the Mountain Loggers Group Safety Initiative (MLGSI). None of the audits conducted by these programs were conducted specifically for this study but were donated in the interest of logging safety research.

The West Virginia Forestry Association Loggers Safety Initiative (WVLSI) was State implemented in conjunction with the West Virginia Workers Compensation Insurance Program, which was effectively a monopoly when this Initiative was first introduced. The WVLSI was an attempt to remedy the problems of high insurance rates associated with workers compensation insurance for loggers in West Virginia caused by historically high claims rates.

Each participating logging company received a 15 percent reduction in their workers compensation insurance costs for joining the program. In return, these companies were required to attend an annual, one day training session on general safety and logging-specific safety and allow three safety audits every year. Those employees using a chainsaw in their everyday task were required to attend the four levels of Game of Logging over a period of four months. Finally, each logging company that failed a regular audit received a follow up within ten days. If they failed the second audit, they could be removed from the program. There were 590 audits from 97 companies that came from the WVLSI program.

The second component of data used in this report was donated by the Mountain Loggers Group. The Mountain Loggers Group Safety Initiative (MLGSI) started in 2006, about the time WVLSI program was coming to an end. The components of the MLGSI were similar to WVLSI, 
including annual safety training, an annual hearing test, the Game of Logging training for timber cutters, and two safety audits per year, using the same audit form as the earlier WVLSI program. The audits from this group were focused in north central/northwest WV and western Maryland and constituted 166 audits from 39 companies used from the MLGSI program. There were 32 companies that participated in both programs

All the audits completed for this research were conducted by a third-party auditing company which used the same auditing criteria over a period of 20 years starting in 1999 and continuing until 2018. In all, 756 separate audits from 104 companies were considered during this study and all were completed by two individuals over that twenty-year period.

\section{Audit Based Data Collection}

All the data were collected using the same audit form throughout the duration of the programs. The audit form was developed specifically for the WVLSI program but used throughout the entire data collection period.

The form is a three-page paper audit (Appendix 1). The audit first collects the names of every person on the site on the date of the audit, the location of the job, and all the equipment being used. The second page consists of five safety related categories, including: Personal Protective Equipment (PPE), General Requirements, Felling/Limbing/Bucking, Mobile Equipment, and Loading/Landing operations. Each section is structured in a yes/no/not applicable configuration with a set number of points available. The score is calculated by dividing the number of "yes" observations for a particular section by the total number of applicable answers for said section and then multiplying that answer by the total overall points for that section. The set number of points available for each section is allotted through a 
weighting process, where more points are given to a section considered more important in terms of safety. There is also a miscellaneous section in each of the five categories to report any unsafe or hazardous acts or conditions observed while completing said section. This is to account for any hazardous circumstances not specifically identified on the audit form itself. The third page is used to determine the total score by summing the weighted sections, with 100 total points available. A detailed listing of each of the five sections of the audit form is presented below.

The first section reviewed PPE, which evaluated everyone on the site, including visitors, for personal protective equipment. This section was worth 30 points and considered each of the following components:

- Hard hat/head protection

- Hearing protection

- Face and eye protection

- Proper footwear (steel or safety toe)

- Cut resistant chaps when running a chainsaw

- Gloves when handling wire rope

The second section was the general section, worth a total of 10 points. It includes basic components such as:

- $\quad$ First aid kits

- Record of monthly safety meetings

- Notebook of written OSHA programs on site

- Properly labeled containers 
- Proper use of lock-out/tag-out procedures

- Proper planning for gas or electrical power lines

- Proper audible/visual communication between workers

The third section deals with felling timber and is worth 30 points. This section was marked fully in compliance if the logging operation utilized a feller-buncher. Manual felling operations were evaluated based on the following criteria:

- Cutters/toppers/fellers were at least two tree-lengths apart

- The presence of functional safety devices on all chainsaws

- Use of proper felling technique (proper hinges, notches, and back cuts)

- Plan and prepare retreat path before cutting

- Assessment of hazards prior to felling trees

- Use of proper chainsaw starting technique

- Proper removal of lodged trees promptly with equipment

- Whether cutters/toppers cut with the chainsaw overhead

The fourth part of the audit examined mobile machinery located on the logging site and if it was being used properly. This section was worth a total of 15 points and includes the following factors for the audit:

- Seat belts available and operational in all machines

- Operational fire extinguishers available and mounted securely

- Intact ROPS and FOPS

- Functional parking brake on all equipment

- Proper winching 
- Attachments were grounded when not in use

- No riders/passengers in or on equipment

- Steps, ladders, and handholds secure and serviceable

- Three-point contact when mounting or dismounting equipment

- No unsecured items in the cab

- 300 feet between workers and mechanical fellers

- No flammables located in the driver compartments

The fifth section was the landing and loading operations, worth a total of 15 points. It considered the following tasks:

- Truck driver exits the cab and moves to a safe area while being loaded

- Working fire extinguishers available and accessible

- No logs loaded above the trailer standards

- Adequate metal standards and cab racks on trucks

- Workers and equipment were safe distance from log inventory

- Loader boom was grounded when not in use

- No booms or loads above ground workers

- 3-point contact when mounting or dismounting equipment

- Steps/ladders/handholds secure and serviceable

- Load binders were attached before leaving the landing

The protocol for completing the audits consisted of the following: once the logging site was reached, the auditor/inspector would start by accounting for everyone on the jobsite and record their names and job tasks. The number of pieces of equipment was also recorded, and the 
work truck was checked for proper paperwork. Then each of the five categories was checked to assure they were up to specifications. What set these inspections apart from typical OSHA inspections was that they examined every aspect of the job. For example, if the felling was being done a mile or more into the forest, the inspector would walk to the felling site, record the observations, and then walk back. Some auditors do not do that thorough an investigation and do not leave the landing, which may omit many hazardous acts/conditions from being observed.

\section{Sample size, data filtering, and pre-processing}

Initially the data were in the form of individual paper audits taken over 20 years, from 1999 to 2018, with 104 cooperating logging companies; 98 from West Virginia, four from western Maryland, and two from Ohio. The audits were sorted by company and the records for each company were compiled together to provide a sample of company compliance over time. For a homogeneous and meaningful sample, the records utilized in the analysis had to meet specific inclusion criteria:

1. Companies that had at least five completed Audits were identified and flagged, put in chronological order by audit dates and company name, and included in the analysis. This first step reduced the audited population from 104 Companies with 756 Audits to 78 Companies with a total of 694 Audits.

2. Remaining Companies were then evaluated on the length of time between chronologically ordered audits. If the length of time between two consecutive audits exceeded 365 days, the observed audits for the company audit stream were separated. This approach was considered appropriate because of the high employee turnover rate in logging, and the use of new/different equipment so that after an entire year without an audit a company was considered to have changed its makeup to the point that it was 
considered two separate Entities for analysis purposes. Furthermore, after a year without an audit, it was assumed that any employees still on the that job would have likely regressed in their safety performance. The example in Table 1 demonstrates a 777-day gap in between Audits three and four. Since this was the case, the first three Audits for company "2" were assigned as Entity 2a, and Audits four through seven were assigned to Entity 2b. Again, it was assumed that after a 365-day period the Entity was considered independent of its origins due to multiple factors listed above. These factors were not examined in this analysis but are common among logging operations.

Table 1. Example of the division of companies into Entities regarding the "no more than 365 days in between audits" criteria

\begin{tabular}{cccccc}
\hline Company & $\begin{array}{c}\text { Original } \\
\text { Audit } \\
\text { number }\end{array}$ & Audit date & $\begin{array}{c}\text { Days in } \\
\text { between } \\
\text { audits }\end{array}$ & Entity & $\begin{array}{c}\text { Audit number } \\
\text { after division }\end{array}$ \\
\hline 2 & 1 & $03 / 04 / 2002$ & 0 & $2 \mathrm{a}$ & 1 \\
2 & 2 & $05 / 10 / 2002$ & 67 & $2 \mathrm{a}$ & 2 \\
2 & 3 & $06 / 12 / 2002$ & 33 & $2 \mathrm{a}$ & 3 \\
2 & 4 & $07 / 28 / 2004$ & $\mathbf{7 7 7}$ & $2 \mathrm{~b}$ & 1 \\
2 & 5 & $06 / 01 / 2005$ & 308 & $2 \mathrm{~b}$ & 2 \\
2 & 6 & $09 / 20 / 2005$ & 111 & $2 \mathrm{~b}$ & 3 \\
2 & 7 & $06 / 14 / 2006$ & 267 & $2 \mathrm{~b}$ & 4 \\
\hline
\end{tabular}

3. Each Entity was required to have a total of at least three consecutive audits to be included in the new data set. For example, in Table 1, Company 2 had seven Audits total with one extended period (>365 days) and was divided into two Entities, 2a having three Audits, and $2 \mathrm{~b}$ having four. If company 2 would have only had five Audits total, ending on 06/01/2005, then Audits four and five would have been excluded due to the lack of three consecutive audit criteria, resulting in a single Entity. Companies in the final data set are referred to as Entities throughout the remainder of this document to avoid confusion 
resulting from the subdivision of Companies. After the 365 day/3 consecutive audit rule the newly resulting data set contained 106 Entities with a total of 653 Audits.

Figure 1 illustrates the progressive effect of sample adjustments on the original data set. It provides the pathway that was taken to sort the initial 104 companies first into 78 companies by only using those that had at least five completed audits, which resulted in 78 companies and 694 Audits. Secondly, the database was sorted using the following criteria, no greater than 365 days between audits and at least 3 consecutive audits completed. This resulted in a total of 653 Audits and 106 Entities.

- Original data paper audits

- 104 Companies, 756 Audits

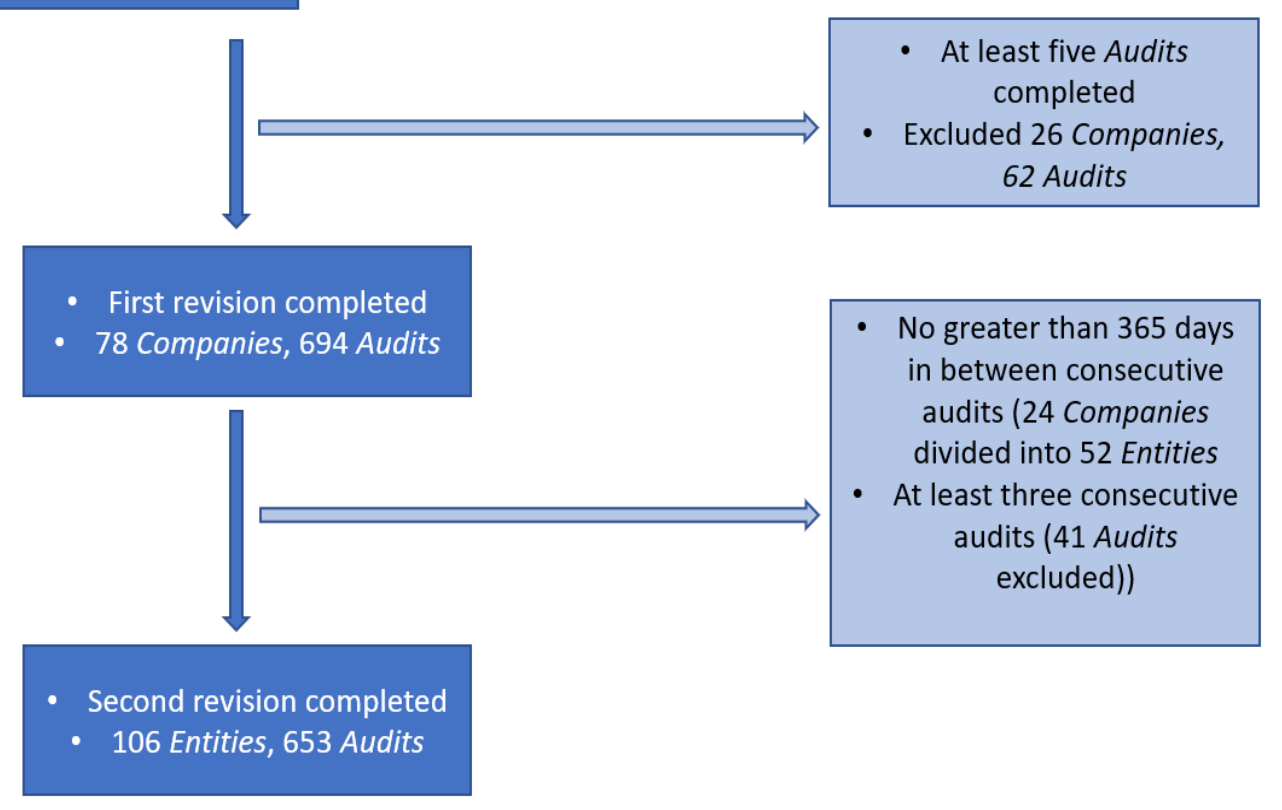

Figure 1. Flow chart of progression of the data modification/preparation before the statistical analysis 


\section{Dependent or Response Variables}

The initial response variable(s) was Days in Compliance for Total Score, which was used in the preliminary set of models. These calculations were completed for PPE and Felling Scores also, these two categories were used because they were the heaviest weighted sections of the audit and therefore the most important in terms of safety. It was developed by combining two parameters: the calendar dates of audits and a variable that identified (via binary outcome) whether at least five percent decrease in the audit score occurred with respect to the previous audit, defined as Recurrence. The change in Total Score was first calculated and only those that had a decrease of five percent or more of the previous score were marked. Seven and a half and ten percent drops in scores were also considered for the preliminary analyses but were not evaluated due to the reduced sample sizes that resulted. The variable Recurrence was created to flag the audits when an Entity had at least a five percent decrease in Total Score from the previous score. This binary variable provided a way to sort the dataset with a binary outcome, so if an Entity had a five percent or more decrease in Total Score from the previous audit, Recurrence was labeled a "Yes", and if a five percent or greater decrease in score did not occur, Recurrence was assigned a value of "No" (Table 2). For statistical analyses the Recurrence values Yes and No were later coded numerically ( $\mathrm{Yes}=1, \mathrm{No}=2$ ).

Days in Compliance Total Score expresses how long an Entity proceeded until a five percent or more decrease in the last audit's Total Score occurred; in this case Recurrence = Yes, in chronological order from one audit date to the next. Once an Entity observed a five percent or more decrease, Days in Compliance was reset to zero and a new day count started from that time point. If an Entity experienced more than one drop, the Days in Compliance would start over from the most recent drop. Table 2 illustrates the history for the Entity_l, with six Audits 
between December 1999 and April 2001. For this example, on Audit No. two (on 2/17/2000), a period of 78 days elapsed between the first and second Audits while the Entity_1 stayed in compliance as the Total Score (92.14) was not lower than five percent of the first Audit's score (71.45). Thus, the Days in Compliance Total Score is $\mathbf{7 8}$ indicating the number of days the Entity stayed without a decrease in Total Score. Later on, the Entity_1 experienced two instances where the Total Score decreased by at least five percent; one on the third Audit (with Total score 87.23 on 5/18/2000) and the other on the sixth Audit (Total Score 87.26 on 4/5/2001), in bold font in Table 2. Days in Compliance for Total Score was calculated as the interval from the first Audit to the third Audit for a total of $\mathbf{1 6 9}$ days, and from the third Audit to the sixth Audit, totaling $\mathbf{3 2 2}$ days. After receiving an Audit where the Total Score dropped by 5 percent on 5/18/2000, the period in compliance was calculated as 63 days (Audit No. 4), and the Entity remained in compliance for a total of $\mathbf{1 7 3}$ days (Audit No.5 on 11/7/2000) before receiving another Audit score where the Total Score dropped by five percent or more (Audit No. 6 on 4/5/2001) (149 days).

If an Entity were audited several times with no five percent decrease in audit score, then only the greatest interval of days where no decrease in score occurred would be considered for the preliminary analysis. Earlier audits for the Entity with all associated Days in Compliance were already accounted for in this value, as the Days in Compliance are cumulative in nature. For example, in Table 2, the Entity_l at Audit No. 5 did not have a five percent decrease in Total Score but stayed in compliance (Days in Compliance) until next Audit, for at least 173 days. Since this number of days already included the non-decrease in Audit No. 4 (Days in Compliance Total Score $=63$ ), only the last, maximal days when compliance was achieved, was recorded and used in preliminary analysis. This approach avoids the same entry from being counted multiple 
times. If, for example, Entity lasted 173 Days in Compliance, there is no need to say they stayed in compliance for 63 days, as 173 days is the much more noticeable achievement. In the preliminary approach, both categories of Recurrence, Yes and No, were utilized, but with the number of total observations reduced to those that had a decrease and those with maximum days without a decrease in score. In the example in Table 2, that would constitute using two rows (Audit No. 3 and $\boldsymbol{6}$ ) as representatives of Recurrence (Yes) and two rows corresponding to lack of Recurrence situations (No, Audit No. 2 and 5), for total of four rows from Entity_1.

However, in the final analysis the Entities without any drop in score were not examined because the overarching goal was for the analysis to focus only on audits where a drop of five percent or more was observed, like the two rows highlighted in bold and italicized in Table 2 (rows of Audit No. 3 and 6).

Table 2. Example of derivation of variables "Days in Compliance for Total score", "No. of Audits from start or Recurrence" or Days in Compliance per Audit", using Entity_1 as an example.

\begin{tabular}{cccccccc}
\hline $\begin{array}{c}\text { Audit } \\
\text { No. }\end{array}$ & Date & $\begin{array}{c}\text { Days in } \\
\text { between } \\
\text { audits }\end{array}$ & $\begin{array}{c}\text { Total } \\
\text { score }\end{array}$ & $\begin{array}{c}\text { Recurrence } \\
\text { (5 percent } \\
\text { drop from } \\
\text { previous) }\end{array}$ & $\begin{array}{c}\text { Days in } \\
\text { Compliance } \\
\text { for Total } \\
\text { score }\end{array}$ & $\begin{array}{c}\text { No. of } \\
\text { audits } \\
\text { from start } \\
\text { or } \\
\text { Recurrence }\end{array}$ & $\begin{array}{c}\text { Days in } \\
\text { Compliance } \\
\text { per audit } \\
\text { (Total) }\end{array}$ \\
\hline 1 & $12 / 1 / 1999$ & 0 & 71.45 & No & & & \\
2 & $2 / 17 / 2000$ & 78 & 92.14 & No & 78 & 1 & 78 \\
3 & $5 / 18 / 2000$ & 91 & 87.23 & Yes & 169 & 2 & 84.5 \\
4 & $7 / 20 / 2000$ & 63 & 90.30 & No & 63 & & \\
5 & $11 / 7 / 2000$ & 110 & 93.78 & No & 173 & 2 & 86.5 \\
6 & $4 / 5 / 2001$ & 149 & 87.26 & Yes & 322 & 3 & 107.33 \\
\hline
\end{tabular}

The final response variable for the analysis was Days in Compliance per Audit (for Total, PPE and Felling). Demonstrated in the last column of Table 2, Days in Compliance per Audit 
was formed by dividing the Days in Compliance Total Score by No. of Audits from start or Recurrence (Table 2). Since some Entities stayed in compliance longer, over more audits than the others, and audits were not done on a regular schedule, this normalization allowed for factoring in the number of audits and combine it with length of time into one variable. For those instances where there was a five or more percent decrease in score $($ Recurrence $=$ Yes $)$, Days in Compliance per Audit (Total) represents the length of time per audit it took to have a decrease of five or more percent in score. This would represent a threshold of time passed between audits, where it is too late to audit to be able to catch a good score without a five or more percent decrease in Total Score. In addition, this "per audit" basis simplified the analyses by reducing number of variables, as well as the interpretation of the models. The output from the Days in Compliance per Audit models provides the user with an estimate of how long until the next 5 percent drop occurs. Again, this was approach was followed for PPE and Felling Scores as well.

For the other instances, where the Recurrence $=\mathbf{N o}$, the variable Days in Compliance per Audit Total represents the length of time between the audits leading to a good (not-decreased more than five percent) score. It would represent how long an Entity would continue without being audited and still keep a good, stable (less than five percent decrease) Total Score. It serves as a subtotal average number of days per audit, or how long the compliance period lasted per audit, before the drop or the end of examining period. Since the column No. Audits from start or Recurrence has data only for rows that had a drop in score (Recurrence $=$ Yes) and for the maximal Days in Compliance Total for Recurrence $=\mathbf{N o}$, the final dataset for the preliminary analysis for the small example in Table 2 would have only the two highlighted (bold and 
italicized) rows since they are the audits that had a 5 percent or more decrease from previous audit.

The data pre-processing as described above was done for not only Total Score, but for PPE, and Felling Scores separately and highlighted in Figure 2. Therefore, in addition to Days in Compliance for Total Score, and Days in Compliance per Audit Total, two final dependent variables were constructed, based on the sub-category scores, namely, for PPE, and Felling, obtaining Days in Compliance per Audit PPE and Days in Compliance per Audit Felling. Again, PPE and Felling were selected for analysis because these two categories were considered the most important in terms of safety and carry the most weight according to the audit scoring. Days in Compliance per Audit had to be calculated separately for each of these types of scores because a company could have received a lower score (5\% or more) in one category and not in another or in Total Score.

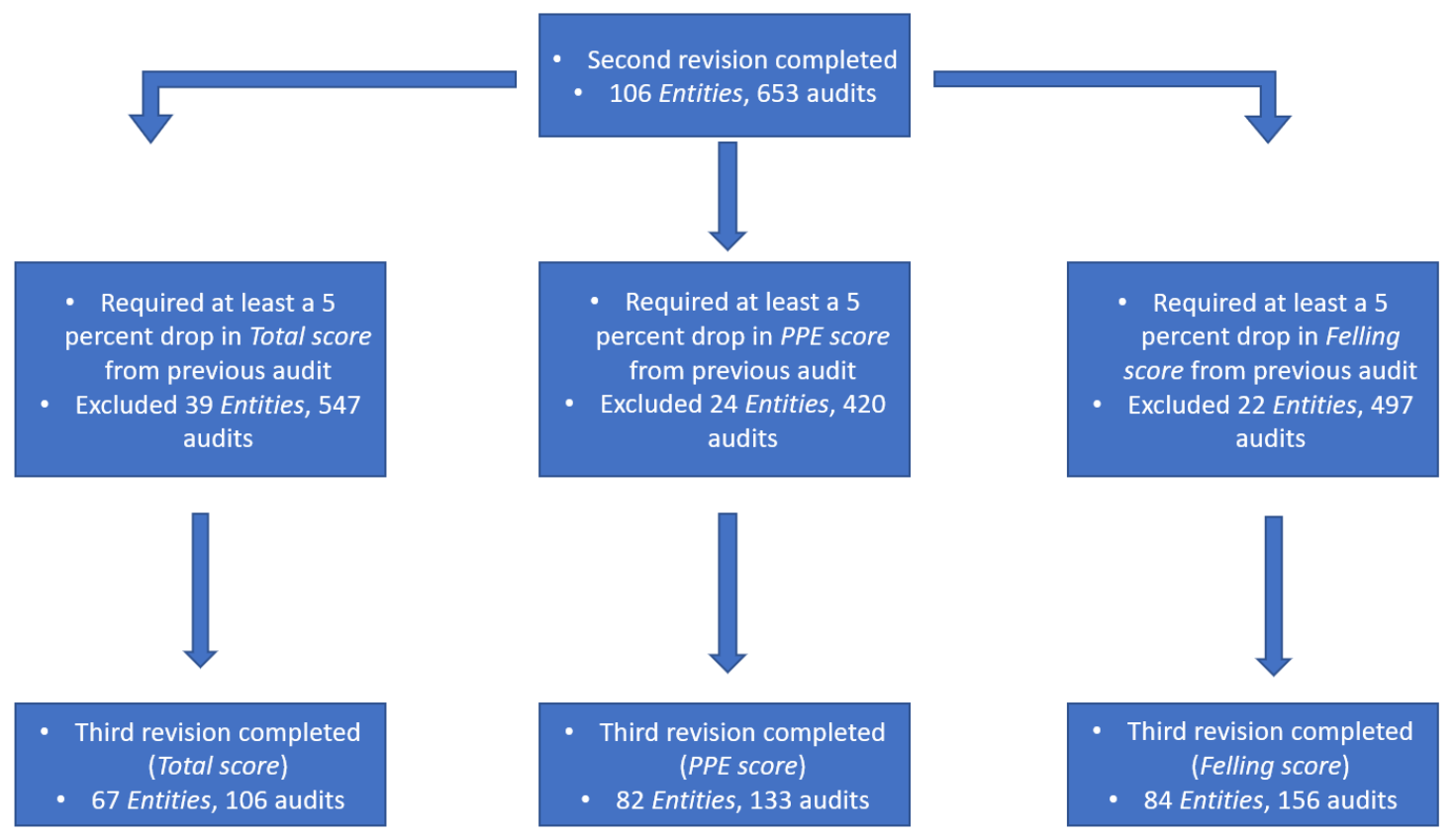

Figure 2. Flow chart presenting how the final database was developed, based on Audit scores that decreased by at least 5 percent from the previous Audit for Total Score, PPE Score, and Felling Score. 
It is important to note that the final statistical models developed during this work ONLY focused on audits and periods between those audits where a five percent decrease in the Total Score was observed relative to the previous audit score. For the example in Table 2, the focus would be on the two Audits on 5/18/2000 and 4/5/2001, in bold red, which resulted in at least a 5 percent drop in Total Score.

The flow chart in Figure 2 outlines the major steps taken to derive the final sample for Total Score and the subcategories of PPE and Felling Score.

\section{Independent Variables}

The independent variables are listed below:

- Company name was recorded for each audit and was defined by the name of the operation. The use of company name allowed audits to be sorted by company and later sorted in chronological order by company. The name was encrypted as a number (with nominal function). Logging company was later referred to as Entity after some of the companies were subdivided into one or more Entities. The Entity variable was used as a random effect in the model and to control for the dependence of multiple Recurrences within the same Entity.

- Personnel represented the number of employees that were on the logging site at the time of the inspection. This would include, but was not limited to foreman, owner, operators (loader, skidder, dozer, etc.), fellers, foresters, and any visitors that were recorded.

- The Audit number (Audit No.) represents the audits a company received, in chronological order. For example, the first audit a Company/Entity received was 
listed as Audit 1, the second was Audit 2, etc. Table 2 illustrates the numbering process for a Company/Entity that received six audits.

- The variable No. of Audits from the start or Recurrence of a five percent decrease in Total Score was calculated by counting the number of days until an Entity observed a five percent drop in Total Score. The initial audit was not considered in developing this variable because there was no comparison to be made with a previous audit. Once a five percent decrease in Total Score was observed, the calculation of the next value of this variable started over. This process was illustrated previously in Table 2, where a decrease of five percent or more occurred on the third Audit from the start so it was labelled as 2 Audits from the start. In addition, a second 5 percent decrease in Total Score occurred on the sixth Audit, so it was three audits from the previous drop. This same process was applied to PPE and Felling Scores.

- Season 1 assigned data into two categories, wet Season, and dry Season. If an audit occurred from May $1^{\text {st }}$ through October $31^{\text {st }}$, Season 1 was considered the dry Season. If an audit occurred from November $1^{\text {st }}$ through April $30^{\text {th }}$, Season 1 was categorized as the wet Season.

- Season 2 was the season in which the audit occurred and was binary - with only two options: warm Season or cold Season. If an audit fell from March $20^{\text {th }}$ through September $20^{\text {th }}$, Season 2 was coded as the warm Season. If an audit occurred from September $21^{\text {st }}$ through March $19^{\text {th }}$, Season 2 was categorized as the cold Season. 
- The final independent variable, termed Mechanized or Non-mechanized, was based on the type of harvesting system used by the Entity and again was binary in nature. The two options - either mechanized to fell trees or manually with a chainsaw - reflect the type of system being used when the audit was conducted. Mechanized systems were coded as a 1, while non-mechanized or manual systems were labeled 0. An Entity could switch from one operation to another at any point in time, so that one audit might list the operation as manual, while the next may list the operation as mechanized.

\section{Normality}

A check for normality for the continuous dependent variables, testing the normality of distribution of their residuals, was conducted using the Shapiro-Wilk W test. For this test, if the p-value was significant at predefined alpha level, then the null hypothesis, representing data fitting a normal distribution, was rejected. An alpha level of 0.05 was set when using this test to determine significance. When a lack of normality was detected an appropriate transformation was sought.

\section{Linear Mixed Models}

Linear mixed models (LMMs) were used to analyze the data. They are similar to general linear models (GLM) except, where GLMs only use fixed effects, LMMs consider both fixed and random effects. The fixed effects used were Personnel, Season and Mechanized status. The random variable in this analysis was Entity, to control for individual Entities and their contribution to the variability of the response. For example, if the Entity variable had a significant p-value in a certain model it provided support that each Entity had a large random 
contribution (differed from one to another) in the variance of Days in Compliance per Audit. In addition, more than one audit within one Entity could have resulted in a decrease in Total Score, acknowledging the existence of, quite possibly, correlation among measurements taken on the same Entity (McCulloch, 2003).

McCulloch (2003) defines the difference between fixed and random effects in the following manner: "If a distribution is assumed for the levels of a factor it is a random factor. If the values are fixed, unknown constants, then it is a fixed factor." In general, fixed effects explain the mean, while random effects explain variance-covariance structure of the dependent variable (Kaps and Lamberson, 2004). The notation used for a linear mixed model follows (Kaps and Lamberson, 2004):

$$
y=X B+Z u+e
$$

where:

$\mathbf{y}=$ Vector of response observations, for instance, Days in Compliance per Audit__Total, PPE or Felling

$\mathbf{X}=($ Fixed) Design matrix for fixed effects (ex. Personnel, Season, Mechanized status), which relate $\mathbf{y}$ to fixed effects $\mathbf{B}$

$\mathbf{B}=$ Independent variables - vector of fixed effects (ex. Personnel, Season, Mechanized status)

$\mathbf{Z}=$ Design matrix, which relate $\mathbf{y}$ to random effects $\mathbf{u}$ (ex. Company or Entity)

$\mathbf{u}=$ Vector of Random effects (with mean 0 and variance-covariance matrix G) (ex. Company or Entity)

$\mathbf{e}=$ Vector of random errors (with mean 0 and variance-covariance matrix R).

To find the solutions for $\mathbf{B}$ and $\mathbf{u}$, mixed model equations were applied within JMP Mixed Model building software (JMP, 2015). The estimators for fixed effects are best linear 
unbiased estimators (BLUE) and the predictors of random effects are known as best linear unbiased predictors (BLUP) (Kaps and Lamberson, 2004). Akaike Information Criterion (AICc) values and computed p-values for the models were evaluated to determine the best models. AICc examines the quality of each model compared to other, similar models, where lower AICc scores suggest a better model. Although AICc does not indicate whether a model was good or bad, it can potentially help select the best model out of multiple models. Individual independent variable $\mathrm{p}$-values were also evaluated to determine which ones explained variability best in the model.

The model analysis was divided into two components. The first response variable, Days in Compliance per Audit Total, examined the period of time from a previous audit in which a five percent drop or more in score was observed. This "total" model accounts for all five audit categories summed up (PPE, General, Felling, Mobile, Landing and Loading sections). The second component considered only one sub-category at a time, Days in Compliance per Audit PPE Score and Days in Compliance per Audit Felling Score, for model development. Again, $P P E$ and Felling were examined because they were the most heavily weighted categories in the audit evaluation.

Data were analyzed using JMP software (JMP®, Version Pro 14.0, SAS Institute Inc., Cary, NC, Copyright (C2015). Significance criterion alpha for all tests was 0.05. 


\section{Results}

\section{Transformations}

Due to the lack of normality in the data, transformations of all three dependent variables were required for the LMMs analysis. The variable Days in Compliance per Audit Total Score was transformed using square root, the variable Days in Compliance per Audit PPE Score was transformed using cube root, while the variable Days in Compliance per Audit Felling Score was transformed using natural $\log (\ln )$.

Table 3. Distributions of the untransformed and transformed dependent variables for only audits that had at least a five percent decrease in scores ( $\mathrm{N}=106$ audits), using Shapiro-Wilk W test. The p-values are included above the graphs.

\section{Distributions for Dependent Variables}

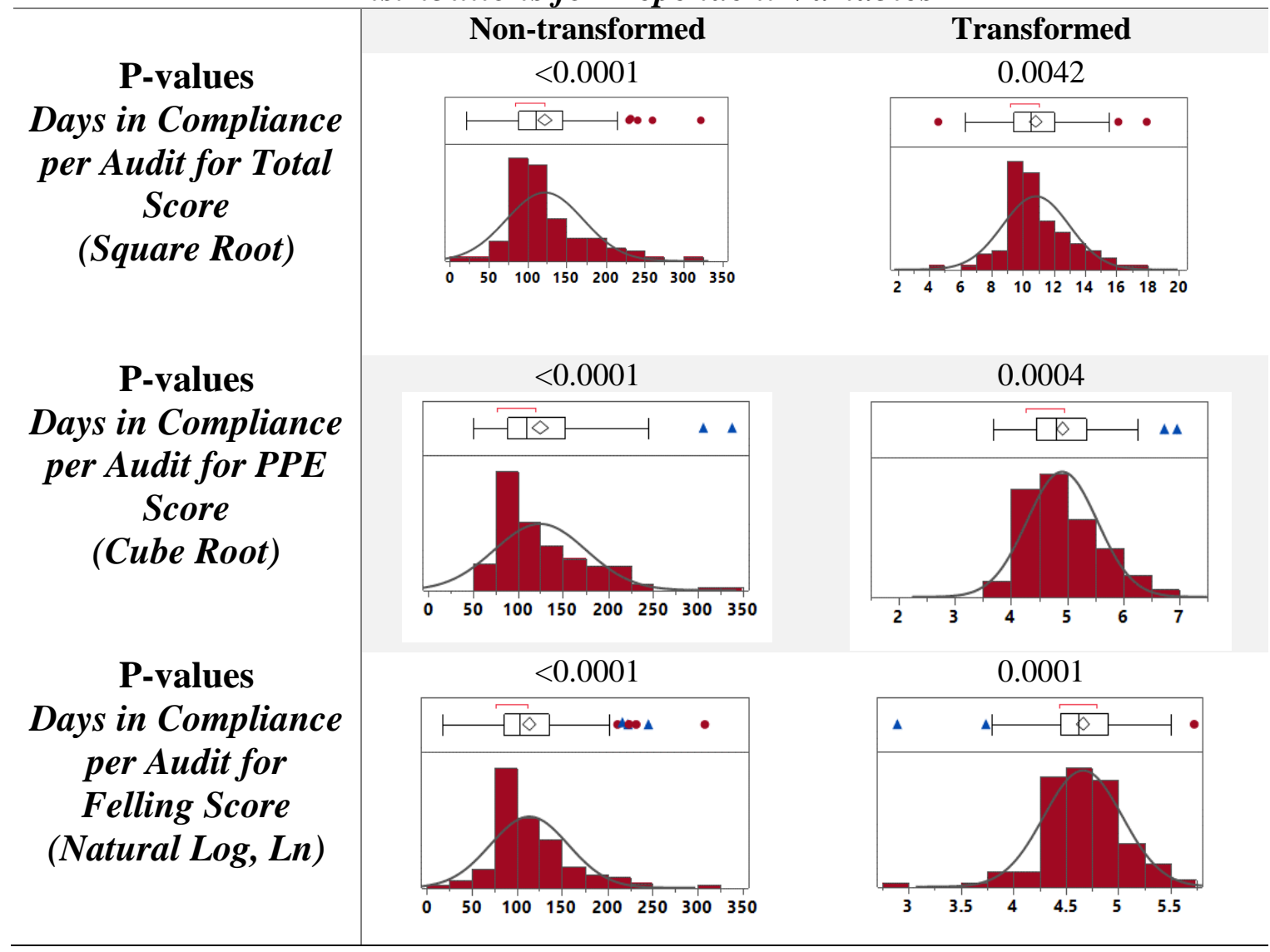


Technically, these transformations did not create perfect normal distributions, but did produce distributions that were closer to a normal distribution than the raw data, which permitted the use of statistical testing procedures for normally distributed data throughout the analysis. Since there are no equivalent non-parametric statistic that could be used this had to suffice. The results listed in Table 3 represent the pre- and post-transformation distributions of the dependent variables (only audits with a drop in score of 5 percent or more). When using the Shapiro-Wilk $\mathrm{W}$ test, a significant $\mathrm{p}$-value equates to a non-normal distribution, so the p-value must be greater than 0.05 to be considered a normal distribution.

\section{Descriptive Statistics of all Variables}

The descriptive statistics are provided in column two of Table 4 and includes the initial set of data after companies that had less than five audits were excluded $(\mathrm{N}=694)$, including those with at least five percent drops (Recurrence $=$ Yes), as well as those where no decrease occurred (Recurrence $=$ No) in Total Score. Column three presents the descriptive statistics after Companies were divided into Entities and the 365-day/3 consecutive audit rules were imposed. Since the intent was to examine only audits with a difference of 5 percent or more relative to the previous audit score, only a portion of column 3 audits were included in the model analysis but observations where no drops in score occurred were included in this table to represent the initial sample.

\section{Descriptive Statistics of the Scores}

Table 5 is an overview of the basic statistics, such as mean, standard deviation, standard error, minimum, maximum, as well as the distribution histograms of three types of scores.

Specifically, Total Scores are followed by scores of the 2 most heavily weighted components of 
audits, PPE, and Felling. The mean for overall Total Score is 92.5 percent, but the focus was on the audits that had a five percent or more drop in score (Recurrence $=$ Yes) which had a mean Total Score of 84.9 percent. When comparing the no drop (Recurrence $=$ No) average of 94.3 percent to the average of Entities with a drop (Recurrence $=$ Yes, 84.9 percent) there was on average a difference of 9.4 percent.

Table 4. Descriptive statistics of the original and modified data sets that are included in the linear mixed model analysis. The continuous variables are represented as the mean $\pm \mathrm{SE}$, (range) and categorical variables are listed as counts (percentages).

\begin{tabular}{lcc}
\hline Variables & N = 694 Audits & N = 653 Audits \\
\hline Companies* & 78 & 106 \\
Average $\boldsymbol{A U D I T S}$ per company & $8.9 \pm 0.48,(5-26)$ & $6.2 \pm 0.19,(3-11)$ \\
Season 1 & $363(52 \%)$ & \\
$\quad$ Wet & $331(48 \%)$ & $345(53 \%)$ \\
$\quad$ Dry & $387(56 \%)$ & $308(47 \%)$ \\
Season 2 & $307(44 \%)$ & $355(54 \%)$ \\
$\quad$ Warm & $188(27 \%)$ & $298(46 \%)$ \\
$\quad$ Cold & $506(73 \%)$ & $175(27 \%)$ \\
SYSTEM TYPE & $5.4 \pm 0.1,(1-19)$ & $478(73 \%)$ \\
$\quad$ Mechanized & $179.6 \pm 10.2$, & $5.5 \pm 0.1,(1-19)$ \\
$\quad$ Non- mechanized & $(0-3284)$ & $104.5 \pm 2.9$, \\
Personnel & & $(0-363)$ \\
Days in between audits & $120(17 \%)$ & $106(16 \%)$ \\
& $574(83 \%)$ & $547(84 \%)$ \\
Recurrence** & & \\
$\quad$ Had at least 5 PERCENT drop (Yes) & & \\
No 5 PERCENT drop (No) & & \\
\end{tabular}

*Company audit histories were reviewed to identify situations where an interval of time exceeding 365 days passed with no audits. Company audit histories where this situation occurred were then screened to identify situations both before and after the 365-day "no audit" period where at least three consecutive audits took place with a period of no more than 365 days passing between any two consecutive audits. Where those cases were identified, companies were divided to create separate Entities such that the original 78 Companies were divided into 106 Entities.

** Total Score was evaluated.

PPE had an average difference of 12.3 percent in PPE Scores between those that did not encounter at least five percent (96.3 percent) drop and those that did (84 percent). Felling had 
the lowest average score for those with at least five percent drop and scores averaged 77.6

percent. There was an average difference of 18.4 percent between the no drops ( 96.3 percent) and those with drops (77.6 percent) in Felling Score.

Table 5. Descriptive statistics for the audits scores that include the Total Score and subcategories of PPE Score and Felling Score. N = 547

\begin{tabular}{|c|c|c|c|}
\hline \multicolumn{4}{|c|}{ Descriptive Statistics for Audit Scores } \\
\hline & All data & $\begin{array}{c}\text { Entities with No } \\
\text { Decrease }\end{array}$ & $\begin{array}{c}\text { Entities with at least } 5 \\
\text { percent decrease }\end{array}$ \\
\hline \multirow{2}{*}{$\begin{array}{l}\text { Total Score } \\
(\max 100 \mathrm{pts})\end{array}$} & . $\quad \cdots \cdots \cdots, 0.001$ & $m=\sqrt{0}-1$ & $\bullet \quad \cdots \bullet \quad \dot{\Delta}$ \\
\hline & $\begin{array}{llllll}50 & 60 & 70 & 80 & 90 & 100\end{array}$ & $\begin{array}{llllll}50 & 60 & 70 & 80 & 90 & 100\end{array}$ & $\begin{array}{llllll}50 & 60 & 70 & 80 & 90 & 100\end{array}$ \\
\hline Mean total audit score & $92.5,92.5 \%(\mathrm{~N}=547)$ & $94.3,94.3 \%(n=441)$ & $84.9,84.9 \%(\mathrm{n}=106)$ \\
\hline Standard deviation & 6.1 & 3.92 & 7.4 \\
\hline Standard error & 0.26 & 0.19 & 0.72 \\
\hline Minimum & 47.7 & 79.0 & 47.7 \\
\hline Maximum & 100 & 100 & 94.7 \\
\hline \multirow[t]{2}{*}{ PPE Score (max 30 pts) } & ・.nm & $\Delta \quad \cdots x-\square$ & 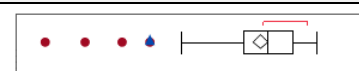 \\
\hline & 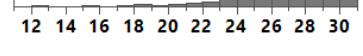 & $\begin{array}{lllllllllll}12 & 14 & 16 & 18 & 20 & 22 & 24 & 26 & 28 & 30\end{array}$ & 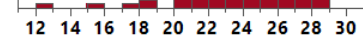 \\
\hline Mean PPE audit score & $28.0,93.3 \%(\mathrm{~N}=547)$ & $28.9,96.3 \%(n=414)$ & $25.2,84.0 \%(\mathrm{n}=133)$ \\
\hline Standard deviation & 2.4 & 1.5 & 2.6 \\
\hline Standard error & 0.10 & 0.07 & 0.23 \\
\hline Minimum & 12.7 & 19.1 & 12.7 \\
\hline Maximum & 30 & 30 & 28.4 \\
\hline \multirow{2}{*}{$\begin{array}{l}\text { Felling Score }(\max 30 \\
\text { pts) }\end{array}$} & - $\quad \operatorname{mos} 10$ & $4+4-0$ & - $\quad \cdots \infty$ \\
\hline & $\begin{array}{lllllll}0 & 5 & 10 & 15 & 20 & 25 & 30\end{array}$ & $\begin{array}{lllllll}0 & 5 & 10 & 15 & 20 & 25 & 30\end{array}$ & $\begin{array}{lllllll}0 & 5 & 10 & 15 & 20 & 25 & 30\end{array}$ \\
\hline $\begin{array}{l}\text { Mean Felling audit } \\
\text { score }\end{array}$ & $27.2,90.6 \%(\mathrm{~N}=547)$ & $28.8,96.0 \%(\mathrm{n}=391)$ & $23.3,77.6 \%(n=156)$ \\
\hline Standard deviation & 3.8 & 2.2 & 4.1 \\
\hline Standard error & 0.16 & 0.11 & 0.33 \\
\hline Minimum & 0 & 20 & 0 \\
\hline Maximum & 30 & 30 & 28.1 \\
\hline
\end{tabular}


The descriptive statistics used in the modeling of Days in Compliance per Audit Total, $P P E$, and Felling are provided in Table 6 and include only those Entities that experienced a drop of 5 percent or more from the previous audit. The leftmost column lists the variables/parameters considered in model development. The second column contains the descriptive statistics for the models predicting Days in Compliance per Audit Total Score. The third and fourth columns provide the descriptive statistics for Days in Compliance per Audit PPE Score and Days in Compliance per Audit Felling Score.

The Entities row in Table 6 illustrates that not all Entitles experienced a drop of 5 percent or more in Total Score, this was also the case for PPE and Felling. The Total Score column indicates that 67 Entities, with 106 Audits experienced a drop in score of 5 percent or more, so some Entities experienced more than one drop. The majority (70 percent) of these Audits were Non-mechanized. The overall mean number of Personnel was 5.9 employees. The mean Days in Compliance Total Score was 318.2 days with a range from 42 to 946 days, while the mean Days in Compliance per Audit Total was 116.7 with a range of 21.3 to 324 . This indicates that the average time it took for an Entity to have at least 5 percent drop in Total Score was 116.7 days from the start of Audits or a previous 5 percent drop.

The third column in Table 6 addresses the PPE component of model analysis. It displays 82 Entities with a total of 133 Audits where at least 5 percent from the previous PPE Score was observed. Also, it reveals that 69 percent of the Entities operated a Non-mechanized crew, with an average of 5.3 employees on the job. It also exhibited the greatest Days in Compliance per Audit PPE value of 117.6 days. 
Table 6. Descriptive statistics of the audits that exhibited at lest 5 percent drop in score from the previous audit. The continuous variables are represented as the mean \pm SE (range) and categorical variables are listed as counts (percentages).

\begin{tabular}{|c|c|c|c|}
\hline VARIABLE & $\begin{array}{c}\text { AT LEAST } 5 \\
\text { PERCENT DROP } \\
\text { IN TOTAL SCORE } \\
\end{array}$ & $\begin{array}{c}\text { AT LEAST } 5 \\
\text { PERCENT DROP IN } \\
\text { PPE SCORE } \\
\end{array}$ & $\begin{array}{c}\text { AT LEAST } 5 \\
\text { PERCENT DROP IN } \\
\text { FELLING SCORE }\end{array}$ \\
\hline ENTITIES (N) & 67 & 82 & 84 \\
\hline $\begin{array}{l}\text { AUDITS } \\
\text { Total no. of at least }\end{array}$ & & & \\
\hline $\begin{array}{l}5 \% \text { decrease in score } \\
\text { Average audit drop } \\
\text { occurred on }\end{array}$ & $4.7+0.2 \cdot(2-11)$ & $4.6 \pm 0.2 \cdot(2-11)$ & $4.6 \pm 0.2 \cdot(2-10)$ \\
\hline SEASON 1 & & & \\
\hline $\begin{array}{l}\text { Wet } \\
\text { Dry }\end{array}$ & $\begin{array}{l}65(61 \%) \\
41(39 \%)\end{array}$ & $\begin{array}{l}69(52 \%) \\
64(48 \%)\end{array}$ & $\begin{array}{l}84(54 \%) \\
72(46 \%)\end{array}$ \\
\hline SEASON 2 & & & \\
\hline $\begin{array}{l}\text { Warm } \\
\text { Cold }\end{array}$ & $\begin{array}{l}53(50 \%) \\
53(50 \%)\end{array}$ & $\begin{array}{l}71(53 \%) \\
62(47 \%)\end{array}$ & $\begin{array}{l}94(60 \%) \\
62(40 \%)\end{array}$ \\
\hline SYSTEM TYPE & & & \\
\hline Mechanized & $32(30 \%)$ & $\begin{array}{l}41(31 \%) \\
92(60 \%)\end{array}$ & $23(15 \%)$ \\
\hline PERSONNEL & $\begin{array}{c}5.9 \pm 0.2 \\
(2-14)\end{array}$ & $\begin{array}{c}5.3 \pm 0.2 \\
(2-13)\end{array}$ & $\begin{array}{c}6.2 \pm 0.2 \\
(2-13)\end{array}$ \\
\hline $\begin{array}{l}\text { DAYS IN } \\
\text { COMPLIANCE }\end{array}$ & $\begin{array}{c}318.2 \pm 20.4 \\
(42-946)\end{array}$ & $\begin{array}{c}310.5 \pm 17.3 \\
(50-1238)\end{array}$ & $\begin{array}{r}278.6 \pm 16.7 \\
(18-1480)\end{array}$ \\
\hline $\begin{array}{l}\text { DAYS IN } \\
\text { COMPLIANCE PER } \\
\text { AUDIT }\end{array}$ & $\begin{array}{r}116.7 \pm 0.04 \\
(21.2-324)\end{array}$ & $\begin{array}{l}117.6 \pm 0.0002 \\
(50.7-343)\end{array}$ & $\begin{array}{l}106 \pm 1.03 \\
(18.9-299)\end{array}$ \\
\hline $\begin{array}{l}\text { DAYS IN } \\
\text { BETWEEN } \\
\text { AUDITS }\end{array}$ & $\begin{array}{c}129.8 \pm 6.6 \\
(16-363)\end{array}$ & $\begin{array}{c}128.5 \pm 5.5 \\
(16-338)\end{array}$ & $\begin{array}{c}115.8 \pm 4.5 \\
(16-363)\end{array}$ \\
\hline $\begin{array}{l}\text { NO. OF AUDITS } \\
\text { FROM START OR } \\
5 \text { PERCENT DROP }\end{array}$ & $\begin{array}{l}2.6 \pm 0.1 \\
\quad(1-8)\end{array}$ & $\begin{array}{l}2.5 \pm 0.1 \\
\quad(1-8)\end{array}$ & $\begin{array}{l}2.4 \pm 0.1 \\
\quad(1-8)\end{array}$ \\
\hline $\begin{array}{l}\text { AVERAGE DROP } \\
\text { IN SCORE }\end{array}$ & $10 \%$ & $12.8 \%$ & $17.2 \%$ \\
\hline
\end{tabular}

The fourth column of Table 6 considers the Felling component of the model analysis. A total of 84 Entities had 156 Audits with drops of 5 percent or more in Felling Score from their previous audit. Of these 156 Audits, 133 (85 percent) were Non-mechanized operations. The average number of Personnel was 6.2 employees. Days in Compliance for Felling averaged 278.6 days with the average No. Audits from start or Recurrence of a 5 percent drop was 2.4, 
while Days in Compliance per Audit averaged 106 days. Days in Compliance per Audit is on a "per audit" basis, while Days in Compliance specifies the average number of at least 5 percent

drops over time, e.g., an average of 2.4 drops spread over a period of 278.6 days or one 5 percent or larger every 116 days of operation. The Felling Score had the highest average drop of 17.2 percent.

\section{Models}

\section{Overview}

The model analysis first tested what are known as the preliminary full models (Table 7). These models were included in the analysis to show the different pathways taken and results for said pathways. The models include all the independent variables, specifically No. of Audits from start or Recurrence of a 5 percent drop, Personnel, Season 1 or Season 2 and Mechanized/Nonmechanized. The dependent variable was Days in Compliance which was later changed to Days in Compliance per Audit for the final set of models. Both Seasons were examined separately starting with Season 1 to determine the better predictor of the two variables. Each model was analyzed, and some variables were excluded until a model was identified that exhibited the most significance and performed the best, based on both p-values and AICc results. 
Table 7. Full models at the beginning stages of the analysis. Each coefficient is listed first followed by the corresponding p-value for that effect. Entries in bold are significant p-values.

\begin{tabular}{|c|c|c|c|c|c|c|}
\hline $\begin{array}{l}\text { Response } \\
\text { Variables } \rightarrow \\
\text { Independent } \\
\text { Variables } \\
\downarrow\end{array}$ & $\begin{array}{c}\text { Days in } \\
\text { Compliance } \\
\text { for Total } \\
\text { Score }(S q \\
\quad R t)\end{array}$ & $\begin{array}{c}\text { Days in } \\
\text { Compliance } \\
\text { for Total } \\
\text { Score } \\
(\text { Sq Rt) }\end{array}$ & $\begin{array}{c}\text { Days in } \\
\text { Compliance } \\
\text { for PPE } \\
\text { Score } \\
\text { (Cube Rt) }\end{array}$ & $\begin{array}{c}\text { Days in } \\
\text { Compliance } \\
\text { for PPE } \\
\text { Score } \\
\text { (Cube Rt) }\end{array}$ & $\begin{array}{l}\text { Days in } \\
\text { Compliance } \\
\text { for Felling } \\
\text { Score (Ln) }\end{array}$ & $\begin{array}{c}\text { Days in } \\
\text { Compliance } \\
\text { for Felling } \\
\text { Score (Ln) }\end{array}$ \\
\hline $\mathrm{AICc} \rightarrow$ & 543.1 & 543 & 317.8 & 314.0 & 166 & 165.2 \\
\hline Intercept & $\begin{aligned} & 10.1 \\
&<\mathbf{0 . 0 0 0 1}\end{aligned}$ & $\begin{array}{c}10.3, \\
<\mathbf{0 . 0 0 0 1}\end{array}$ & $\begin{aligned} & 4.91 \\
< & \mathbf{0 . 0 0 0 1}\end{aligned}$ & $\begin{aligned} & 4.95 \\
< & \mathbf{0 . 0 0 0 1}\end{aligned}$ & $\begin{aligned} & 4.42 \\
< & \mathbf{0 . 0 0 0 1}\end{aligned}$ & $\begin{array}{c}4.46 \\
<\mathbf{0 . 0 0 0 1}\end{array}$ \\
\hline Audits & $\begin{array}{c}3.11, \\
<\mathbf{0 . 0 0 0 1}\end{array}$ & $\begin{array}{c}3.10 \\
<\mathbf{0 . 0 0 0 1}\end{array}$ & $\begin{array}{c}0.86 \\
<\mathbf{0 . 0 0 0 1}\end{array}$ & $\begin{array}{c}0.86 \\
<\mathbf{0 . 0 0 0 1}\end{array}$ & $\begin{array}{c}0.44, \\
<\mathbf{0 . 0 0 0 1}\end{array}$ & $\begin{array}{c}0.44 \\
<\mathbf{0 . 0 0 0 1}\end{array}$ \\
\hline Personnel & $-0.23,0.064$ & $-0.024,0.06$ & $-0.01, \mathbf{0 . 0 0 2}$ & $\begin{array}{l}-0.11, \\
\mathbf{0 . 0 0 1 0}\end{array}$ & $-0.021,0.11$ & $-0.02,0.09$ \\
\hline $\begin{array}{l}\text { Season } 1- \\
\text { Wet, } \\
\text { Dry }\end{array}$ & $\begin{array}{c}-0.42,0.17 \\
0.42,0.17\end{array}$ & & $\begin{array}{c}-0.12,0.07 \\
0.12,0.07\end{array}$ & & $\begin{array}{c}-0.07, \mathbf{0 . 0 3} \\
0.07, \mathbf{0 . 0 3}\end{array}$ & \\
\hline $\begin{array}{l}\text { Season } 2 \\
\text { Cold } \\
\text { Warm }\end{array}$ & & $\begin{array}{c}0.42,0.15 \\
-0.42,0.15\end{array}$ & & $\begin{array}{c}0.18, \mathbf{0 . 0 0 8} \\
-0.18, \mathbf{0 . 0 0 8}\end{array}$ & & $\begin{array}{c}0.08, \mathbf{0 . 0 2} \\
-0.08, \mathbf{0 . 0 2}\end{array}$ \\
\hline $\begin{array}{l}\text { Non- } \\
\text { Mechanized } \\
\text { or } \\
\text { Mechanized }\end{array}$ & $\begin{array}{l}-0.24,0.48 \\
0.24,0.48\end{array}$ & $\begin{array}{c}-0.22,0.52 \\
0.22,0.52\end{array}$ & $\begin{array}{c}-0.01,0.22 \\
0.01,0.22\end{array}$ & $\begin{array}{c}-0.08,0.29 \\
0.08,0.29\end{array}$ & $\begin{array}{c}0.06,0.19 \\
-0.06,0.19\end{array}$ & $\begin{array}{c}0.05,0.28 \\
-0.05,0.28\end{array}$ \\
\hline $\begin{array}{l}\text { Entity } \\
\text { (random } \\
\text { variable) p- } \\
\text { values only }\end{array}$ & 0.35 & 0.3 & 0.22 & 0.08 & 0.55 & 0.47 \\
\hline
\end{tabular}

The three final models (Total, PPE, and Felling) for Days in Compliance per Audit are listed in Table 8. These models are different from the more preliminary full models (Table 7). This was done by dividing Days in Compliance by No. of Audits from start or Recurrence of at least 5 percent drop, making it Days in Compliance per Audit. In the final models the response variable is normalized to number of audits, which is different than the preliminary models that must have an input for the No. of Audits from start or Recurrence of at least 5 percent drop accounted for. All the final models include the same variables: Season 2, and Personnel and a 
random variable of Entity. Personnel was significant throughout, except in the model for Total Score (in which it was very close to being significant). The coefficient for Personnel was negative, meaning that as Personnel increases, Days in Compliance per Audit decreases. In all the models, Season 2 had calculated p-values that were significant, and in every model Season 2 had a positive influence on the Days in Compliance per Audit during the cold Season. So, during the cold Season, Days in Compliance per Audit increases, while during the warm Season, Days in Compliance per Audit decreases. Season 1 was excluded because the lack of significance in the final set of models. The final models are reviewed and discussed in greater detail below.

Table 8. Final models used in the analysis that only examine Audits where a drop of 5 percent or more in score was observed. The coefficient is listed first, then the p-value. Significant p-values are in bold.

\begin{tabular}{lccc}
\hline Response Variables $\rightarrow$ & $\begin{array}{c}\text { Days in Compliance } \\
\text { per Audit for Total } \\
\text { Score }\end{array}$ & $\begin{array}{c}\text { Days in Compliance } \\
\text { per Audit for PPE } \\
\text { Score }\end{array}$ & $\begin{array}{c}\text { Days in Compliance } \\
\text { per Audit for Felling } \\
\text { Score }\end{array}$ \\
\hline AICc $\rightarrow$ & 458.8 & 238.6 & 130.6 \\
Intercept & 11.8, & 5.30, & 4.85, \\
Personnel & $<\mathbf{0 . 0 0 0 1}$ & $<\mathbf{0 . 0 0 0 1}$ & $<\mathbf{0 . 0 0 0 1}$ \\
Season 2 & -0.16, & -0.06, & -0.03, \\
warm, & 0.06 & $\mathbf{0 . 0 0 8}$ & $\mathbf{0 . 0 1}$ \\
cold & $-0.46, \mathbf{0 . 0 2}$ & $-0.18, \mathbf{0 . 0 0 0 4}$ & $-0.09, \mathbf{0 . 0 0 3}$ \\
Entity (random variable) & $0.46, \mathbf{0 . 0 2}$ & $0.18, \mathbf{0 . 0 0 0 4}$ & $0.09, \mathbf{0 . 0 0 3}$ \\
\hline
\end{tabular}

The random variable Entity has the p-value listed on the bottoms of Tables 7 and 8 . The PPE model was the only one in which the random variable Entity could impact the outcome of Days in Compliance per Audit PPE significantly from one Entity to another, meaning that the Days in Compliance per Audit PPE could increase or decrease with changes in Entities. On the other hand, the Total and Felling models Days in Compliance per Audit were not affected by the changing of Entities. 


\section{Days in Compliance per Audit Total - Model 1}

The response variable Days in Compliance per Audit Total was transformed using a square root (Table 8). Independent variables included, Season 2 (warm/cold) and Personnel. Entity was classified as a random variable, as it was in all other models. The only fixed variable that was not significant in the final model for Total was Personnel which was borderline having a p-value of 0.06. Season 2 was significant and impacted Days in Compliance per Audit Total positively in the cold Season and negatively in the warm Season.

The equation for the Total Score model is presented below: When using the equation for warm Season the sign on the coefficient must be changed to negative $(-0.46)$. The estimated model for cold Season is:

Days in Compliance per Audit Total $=[11.8-0.16(\text { Personnel })+0.46]^{2}$

The estimated model for the warm Season is:

Days in Compliance per Audit Total $=[11.8-0.16(\text { Personnel })-0.46]^{2}$

The estimates generated from these equations were put into tabular form to showcase changes in Personnel and cold and warm Seasons (Season 2). Table 9 shows how Days in Compliance per Audit Total changes with the changes in Personnel from the warm Season to cold Season. For example, if an Entity had four Personnel working in the warm Season, their estimated Days in Compliance per Audit Total until a predicted drop in score of at least 5 percent would be $[11.8-0.16(4)-0.46]^{2}=114$ days. Figure 3 depicts the results in Table 9 in a bar graph. The model for Total Score has a range for personnel of 2 through 14 and should not be used outside of this range to maintain accuracy. 
Table 9. Estimates of Days in Compliance per Audit Total according to changes in Personnel and Season 2 from Model 1.

\begin{tabular}{cccccccccl}
\hline \multicolumn{10}{c}{ Days in Compliance per Audit Total } \\
\hline Personnel & 2 & 3 & 4 & 5 & 6 & 7 & 8 & 9 & 10 \\
Cold & 143 & 139 & 135 & 131 & 128 & 124 & 121 & 117 & 114 \\
Warm & 121 & 118 & 114 & 111 & 108 & 104 & 101 & 98 & 95 \\
Average & 132 & 128 & 125 & 121 & 118 & 114 & 111 & 108 & 104 \\
\hline
\end{tabular}

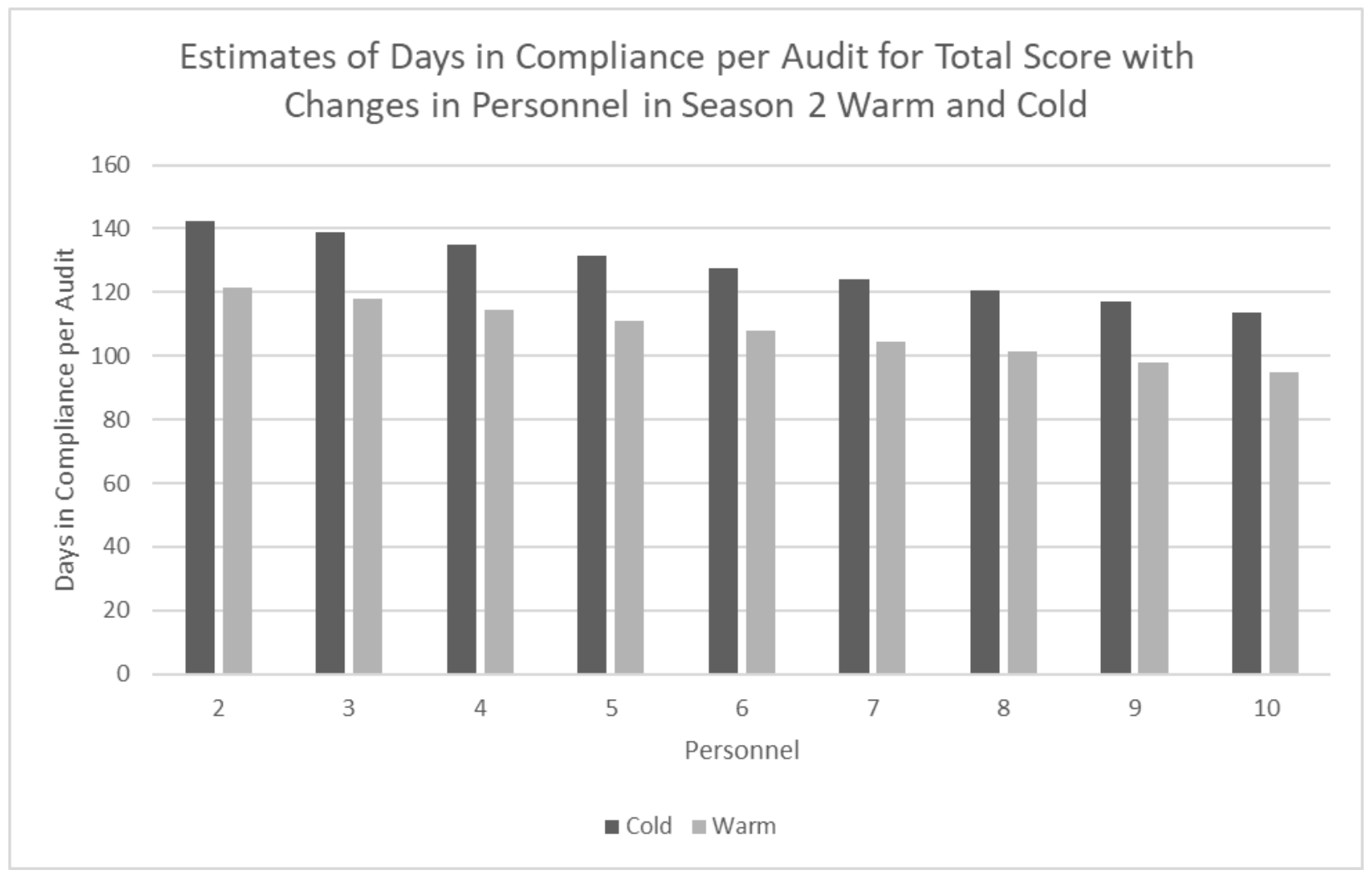

Figure 3. Bar graph of Days in Compliance per Audit for Total Score estimates with changes in Personnel in Season 2 warm and cold. The figure depicts 2 through 10 Personnel but the model can be used to estimate up to 14 Personnel. 


\section{Days in Compliance per Audit PPE - Model 2}

The second model was the PPE model and used Days in Compliance per Audit PPE Score as the dependent variable. The dependent variable was transformed using cube root to approximate a normal distribution. The independent variables included Season 2 (warm/cold) and Personnel (Table 8). All the variables are significant for the final model including the random variable Entity. The random variable does not have to be adjusted for, but the user must be aware that the response could vary from one Entity to another when the random variable is significant. Personnel was significant and impacted Days in Compliance per Audit PPE negatively, which means that the more workers on the logging site, the less time the Entity has before encountering a drop in the audit score of 5 percent or more. This implies that the presence of more people on the job equates to more opportunity for safety violations. For instance, the probability of PPE safety infractions with 10 workers is much greater than with 2 or 3 workers.

Season 2 was also significant and had a positive impact on the Days in Compliance per Audit PPE for the cold Season meaning that Days in Compliance per Audit PPE increases during the cold Season. This could be due to workers not wanting to wear PPE during the hotter months of the year. On the other hand, gloves, chaps, boots, and hard hats would help keep workers warm during the cold months making the PPE more comfortable to wear, so this too could be a contributing factor. The equation for the final model is listed below. Again, when using the equation for warm Season the sign must be changed to negative (-0.18). The estimated model for cold Season is: 
Days in Compliance per Audit PPE $=[5.3-0.06(\text { Personnel })+0.18]^{3}$

The estimated model for warm Season:

Days in Compliance per Audit PPE $=[5.3-0.06(\text { Personnel })-0.18]^{3}$

The estimated values for the $P P E$ equation are provided in Table 10 and Figure 4. Table 10 provides the estimates for a single PPE audit and varies Personnel from two to ten employees in Season 2 (warm/cold) but could be used up to the max range of 13 Personnel accurately.

Table 10. Estimates of Days in Compliance per Audit for PPE Score according to changes in Personnel and Season 2 from Model 2.

\begin{tabular}{cccccccccc}
\hline \multicolumn{10}{c}{ Days in Compliance per Audit PPE } \\
\hline Personnel & 2 & 3 & 4 & 5 & 6 & 7 & 8 & 9 & 10 \\
Cold & 154 & 149 & 144 & 139 & 134 & 130 & 125 & 121 & 116 \\
Warm & 125 & 121 & 116 & 112 & 108 & 104 & 100 & 96 & 92 \\
Average & 139 & 135 & 130 & 125 & 121 & 117 & 112 & 108 & 104 \\
\hline
\end{tabular}




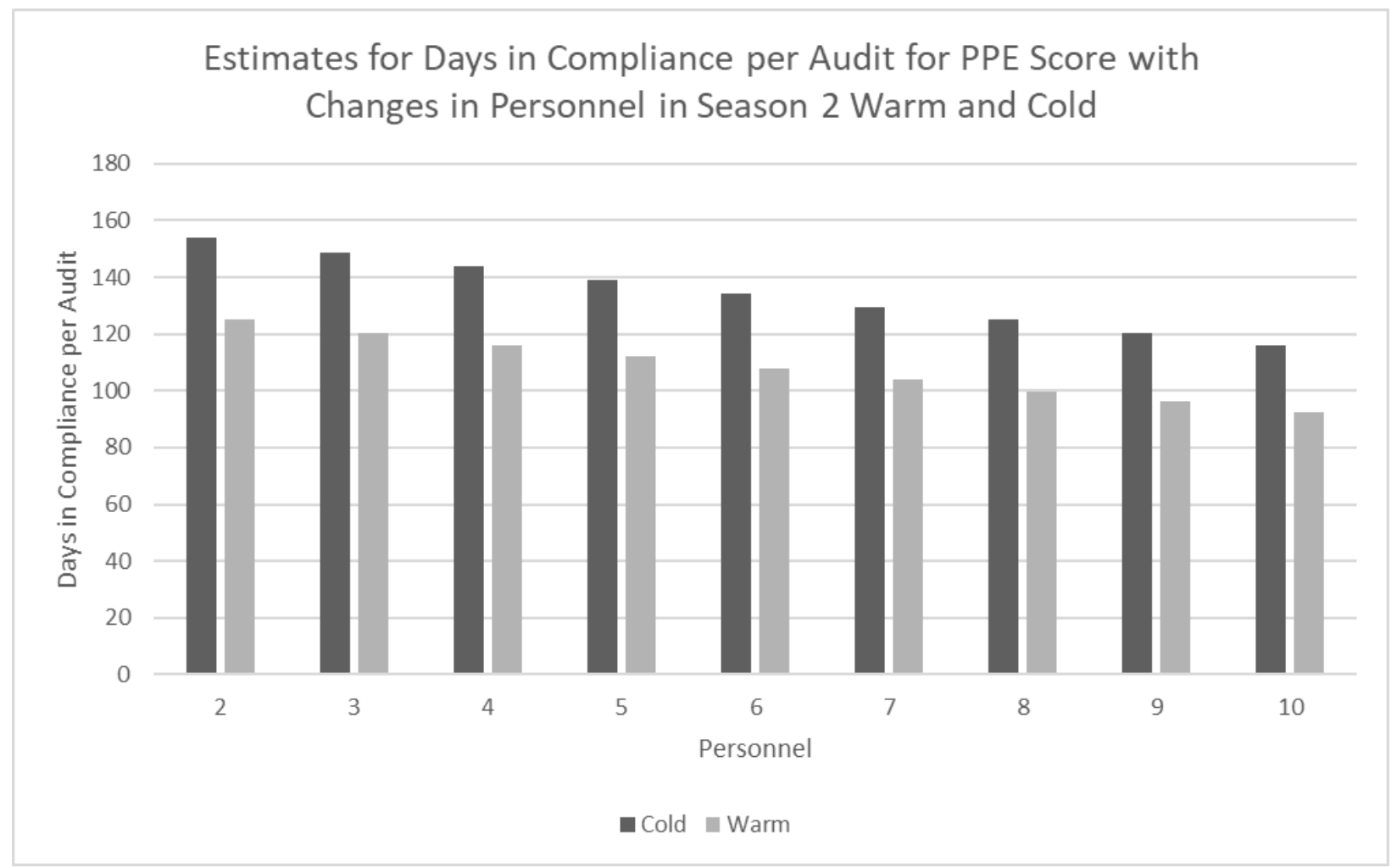

Figure 4. Bar graph of Days in Compliance per Audit for PPE Score estimates with changing Personnel in the warm and cold Season. The figure depicts 2 through 10 Personnel but the model can be used to estimate up to 13 Personnel.

\section{Days in Compliance per Audit Felling - Model 3}

In the model for Felling, the Days in Compliance per Audit Felling as the dependent variable was transformed using natural $\log (\ln )$ to approximate a normal distribution. (Table 8). Independent variables included Season 2 (warm/cold) and Personnel. Entity was classed as a random variable, as it was in all models. The only variable that was not significant in the final model for Felling was the random variable Entity. Personnel was significant and impacted Days in Compliance per Audit Felling negatively. Season 2 was also significant, producing a positive effect on Days in Compliance per Audit Felling during the cold Season and producing a negative 
effect during the warm Season. Again, when using the equation in warm Season the sign must be changed to negative (-0.09). The estimated model for the cold Season is:

Days in compliance per Audit Felling $=e^{\wedge}[4.85-0.03($ Personnel $)+0.09]$

The estimated model for the warm Season is:

Days in compliance per Audit Felling $=e^{\wedge}[4.85-0.03($ Personnel $)-0.09]$

The outputs for this equation are provided in Table 11. The table provides estimates for Days in Compliance per Audit Felling Score with changes in Personnel (from two through ten employees) for Season 2 (warm/cold) but could effectively be used up to 13 Personnel modelbased predicted average period of time that passes prior to a notable drop in audit score in the case of warm season and 10 employees, 86 days (Fig. 7 - Warm, 10 Personnel). By using the shortest number of days, the auditor would generally err on the side of safety and generally ensure that the logging company generally would not regress from what was achieved during the previous audit.

Table 11. Estimates of Days in Compliance per Audit for Felling Score according to changes in Personnel and Season 2, based on Model 3.

\begin{tabular}{ccccccccccc}
\hline \multicolumn{10}{c}{ Days in Compliance per Audit Felling } \\
\hline Personnel & 2 & 3 & 4 & 5 & 6 & 7 & 8 & 9 & 10 \\
Cold & 132 & 128 & 124 & 120 & 117 & 113 & 110 & 107 & 104 \\
Warm & 110 & 107 & 104 & 100 & 98 & 95 & 92 & 89 & 86 \\
Average & 121 & 117 & 114 & 110 & 107 & 104 & 101 & 98 & 95 \\
\hline
\end{tabular}

Figure 5 provides the results from Table 11 in a graphical form. 


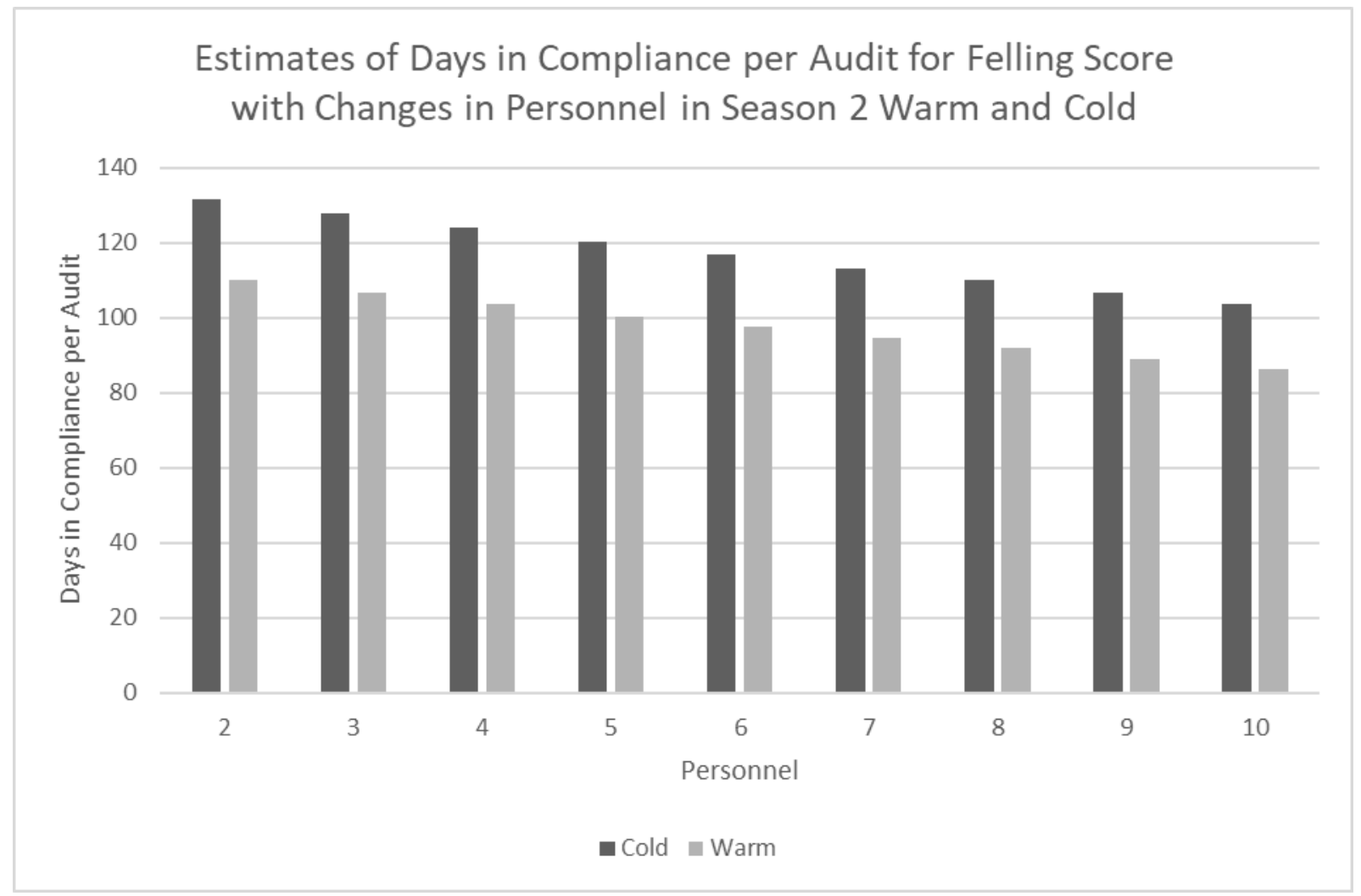

Figure 5. Bar graph of Days in Compliance per Audit for Felling Score estimates when changing Personnel in Season 2 warm and cold. The figure depicts 2 through 10 Personnel but the model can be used to estimate up to 13 Personnel.

All three final models for Days in Compliance per Audit for Total, PPE and Felling in the form of linear lines are plotted in Figures 6 and 7, for warm and cold season, respectively. They show the parallelism of the negative slope indicating increasing numbers of employees decreases the length of period to the next audit if the drop in the audit scores should be prevented. In addition, both figures indicate that the smallest predicted days of compliance in either season are for the felling.

In summary, models predicting the length of time of regular audits to prevent regressing in the audit scores for Total, PPE and Felling, were developed for subset of logging companies with issues with persistence of the safety audit scores. 


\section{Discussion and Conclusions}

This study was designed to investigate logging company safety performance based on a series of safety audits over time. It is presumed that safety audits could have an impact on a company's safety performance over time, by analyzing audit score data, Days in Compliance per Audit with the auditing system, and the characteristics of a company and/or the conditions they are working in. This analysis particularly targeted the portion of the logging company population that are weak performers and will tend to regress over time in their safety performance.

Results suggest that certain variables impact Days in Compliance per Audit significantly. The Total Score model was not affected as much by Personnel, but it was still close enough to significance to be reported. Personnel was significant in the other two models and had a negative impact in all three of the models, again, this could be due to the increased number of possible violations with a greater amount of people on the logging site. Season 2 was significant in all three models but had the strongest p-value in the PPE Score model. As mentioned earlier, this could be due to the comfortability of PPE clothing in certain weather conditions. The random variable of Entity was significant in the $P P E$ model but did not play a significant role throughout.

PPE plays an important role when it comes to safety in any occupation, where it puts a barrier between the worker and a hazard. It is basically a logger's first line of defense. If logging companies could keep their workers using the appropriate PPE during active work periods, it could potentially reduce accidents. Being able to utilize this model allows the user to 
estimate how long they can go before their PPE Score will drop by at least 5 percent, as well as illustrates how some factors, like a change in season, affect its use by employees. A weekly safety meeting reminding employees to utilize their PPE could be a good way to mitigate the drops in score.

Felling can be safely described as the most hazardous occupation on the logging site, particularly for non-mechanized crews where a chainsaw is an indispensable tool for felling trees. As mentioned in the literature review, the OHSA accident data (OHSA, 2017) suggests that most logging accidents involve a chainsaw. The tool itself is hazardous enough, but when felling large trees and while working around heavy equipment, the potential hazards rise exponentially. The model could be extremely helpful by promoting timely audits to keep safety at the forefront of the crew's thoughts during non-mechanized operations, particularly when felling with a chainsaw. Both Personnel and Season 2 (warm/cold) were significant in the Felling model. Personnel impacted the model negatively, so the inference could be made that the more employees there are the more hazards encountered. Educating fellers about the importance of hazard recognition and how to mitigate those hazards could be a way to turn that around. A tool to accomplish this could be an audit program. Simply by going over the checklist on the audit form and ensuring that employees understand what causes issues during an audit would help them more easily recognize work safety issues and perhaps address them before an accident happens.

It is important to remember that not all companies in this study experienced at least 5 percent drop in score. Approximately 84 percent of the Audits or 37 percent of the Entities DID NOT have a drop in Total Score. As with any population, there will be strong performers and weaker performers. The strong performers will have a solid commitment to safety and will be 
the least likely to incur accidents and submit costly workers compensation claims. Auditing for safety performance is one method for separating strong performers from weak performers. At the same time, it is important to note that declining audit scores DO NOT necessarily equate to increased frequency of accidents and workers compensation claims.

One way to begin utilizing the system of models developed here is for a workers compensation insurance carrier to implement an audit plan. The first step would be to perform a baseline audit as a control for future comparisons. This could be an initial audit of a new logging company customer or perhaps a recent audit of an existing logging company customer. This initial audit can provide the insurance company insight into the overall safety performance of the logging company and the opportunity to help the logging company recognize vulnerabilities in their safety program and allow them to make improvements before the next audit. The baseline audit could also serve as the basis for determining the number of days until the next audit. Tables 9, 10, and 11 along with Figures 3, 4, and 5 offer insight into how periodic audits can help maintain audits scores, and theoretically help logging companies avoid accidents.

In turn, insurance companies could use this approach to better strategize how to best use their resources to audit logging companies. By incorporating specifics for a logging company into the equation and using the output to setup an audit timeline program, a schedule could be developed for conducting audits that focuses on maintaining a high level of safety over extended periods of time.

For example, if an insurance company took on a new company or if a company had just experienced a significant drop in their audit score, how long could they reasonably wait to conduct another safety audit before the company would experience a drop in safety performance or audit score? Using Table 9, if the company had five Personnel in the warm Season, the 
estimated duration of compliance before a drop in the audit score is approximately 111 days. The insurance company could conduct a follow-up audit within that 111-day period to maximize safety compliance and minimize any potential drop in safety related behavior that might ultimately lead to continued poor performance and the possibility of an accident claim.

The final models developed here used number of Personnel and Season 2 (warm/cold) to estimate the amount of time before the next audit would yield a score that would drop notably, namely, at least 5 percent of eh previous score. The estimated time to the next significant drop in audit score was determined in three ways, by comparing the Days in Compliance per Audit Total Score (Table 9), PPE Score (Table 10), and Felling Score (Table 11). Given that all the three models predict the amount of time prior to regressing in the audit scores, insurance company auditors can use them collectively to estimate the shortest length of time to the next drop in audit score.

In the case of the warm Season, the minimum number of days, across the number of Personnel, one could anticipate at least 5 percent drop in Felling audit score is provided in Table 11. The number of Days in Compliance per Audit Felling ranges from 132 days for 2 workers, to 86 days for 10 workers. Total Score and PPE Score Days in Compliance per Audit showed ranges of 143 to 95 for Total Score (Table 9) and 154 to 92 for PPE Score (Table 10), respectively, indicating that because of the lowest values, the Felling Scores should be used when estimating the number of Days in Compliance per Audit. The situation with the cold Season estimates is similar to the warm Season results, in that the minimum number of Days in Compliance per Audit occurs for the Felling Score.

One important thing to note is that the lines for Total and PPE Scores in Figure 6 cross at Personnel $=8$, so that PPE Score becomes more important than Total Score for 8, 9, and 10 
Personnel during the warm Season. Figures 6 and 7 showcase the slope of Days in Compliance per Audit for each model illustrating that Felling has the lowest number of Days in Compliance per Audit.

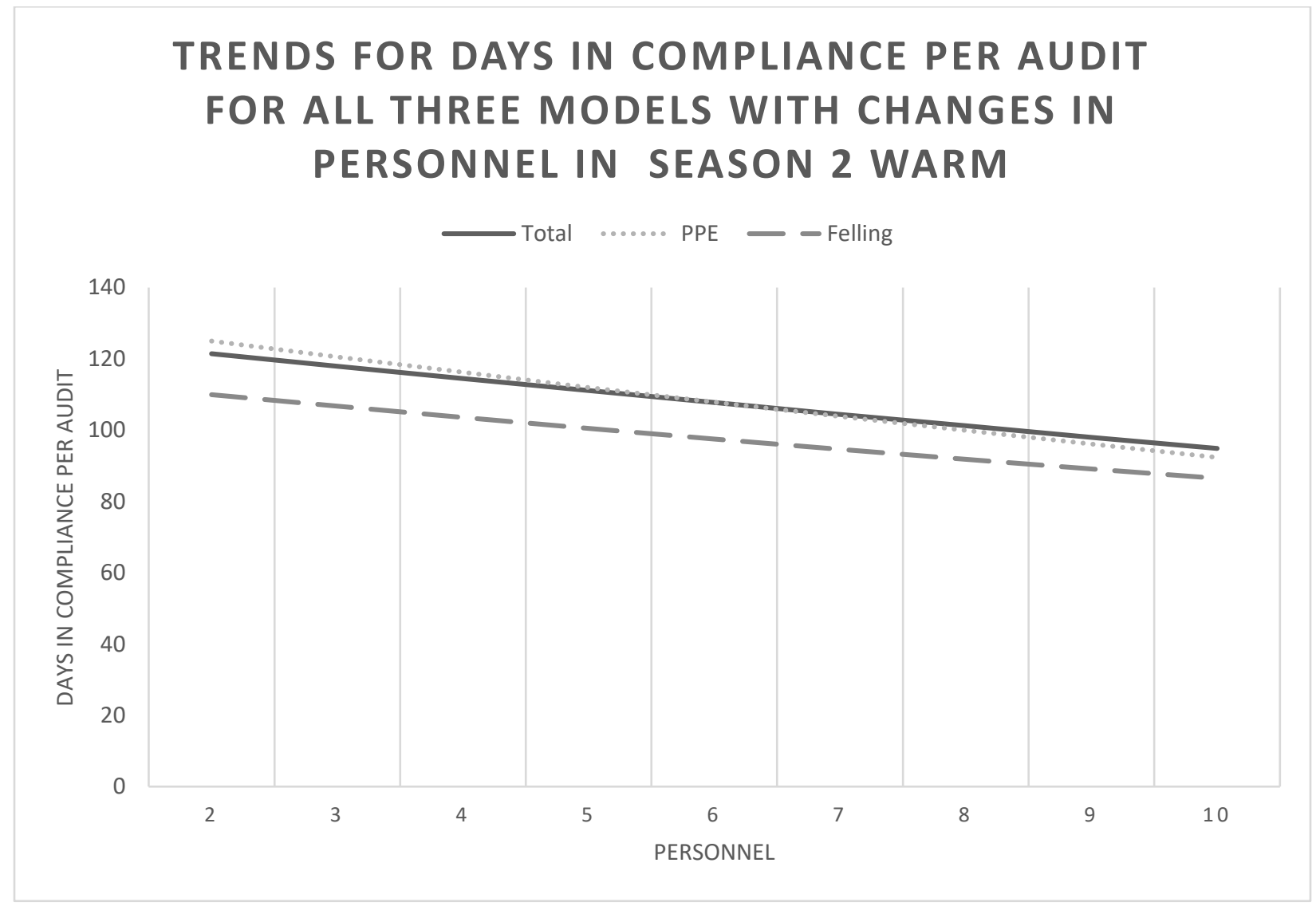

Figure 6. Trendlines of all three models Days in Compliance per Audit casing the intersection of Total and PPE in the warm Season. 


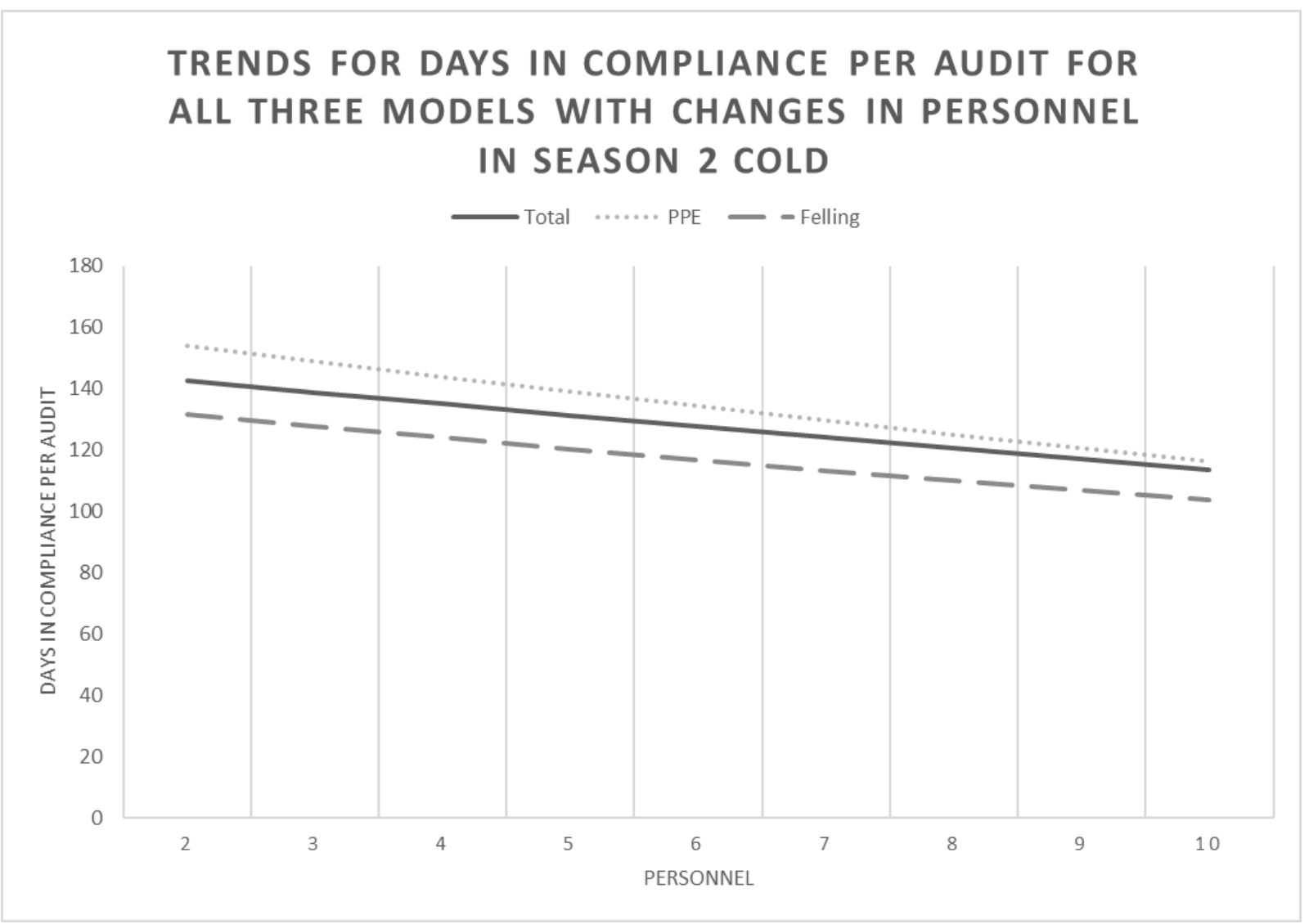

Figure 7. Trendlines of all three models Days in Compliance per Audit casing the possibly approaching intersection of Total and PPE in the cold Season.

For application purposes, the use of the models is very straightforward and only relies on which model to use in each situation. For instance, although the variable mechanized v. nonmechanized was not statistically significant, it would be reasonable to conclude that, for a mechanized logging operation, either the Total Score or PPE Score model might be more appropriate, since all felling involves mechanical operations.

Very little attention has been paid to auditing research in the public domain, due primarily to the lack of available audit data. That is not to say that insurance companies have not investigated and analyzed their internal auditing in some way. For those insurance companies that have not investigated their auditing systems, this research could provide some basic insights 
into how they might view their auditing protocols, which could lead to more efficient allocation of auditing resources with respect to logging companies. This study could also provide some insights into how an insurance company might structure their field auditing procedures to better understand the logging company's safety performance. The audit form in Appendix 1 could serve as a basis for that. Audit scoring could also be used as an incentive tool. That is, a logging company could receive a policy discount from their insurer for continued excellence in their audit score performance.

A next logical step in the evolution in this research could be the pairing of safety audits with accident and injury data, to better quantify the relationship of falling audit scores with the occurrence and frequency of accidents/injuries and the accompanying workers compensation claims. This could ultimately determine if the cost of auditing can at least be offset by better claims performance on the part of logging company policy holders.

In conclusion, by utilizing the models and educating the loggers, we can potentially help raise audit-based safety scores. Therefore, creating opportunities to reduce work related injuries and even deaths, perhaps the only real goal of this work. 


\section{References}

Bell, J. 2002. Changes in logging injury rates associated with use of feller-bunchers in West Virginia. Journal of Safety Research, 33(4), 463-71.

Bell, J., \& Grushecky, S.T. 2006. Evaluating the effectiveness of a logger safety training program. Journal of Safety Research, 37(1), 53-61.

Bell, Jennifer L, and James C Helmkamp. 2003. Non-Fatal Injuries in the West Virginia Logging Industry: Using Workers' Compensation Claims to Assess Risk from 1995 through 2001. American Journal of Industrial Medicine, 44(5), pp. 502-509.

Bonauto, David K., Wuellner, Sara E., Marcum, Jennifer L. \& Adams, Darrin A. 2019 Injury Rate Comparisons for Nonmechanized and Mechanized Logging Operations, Washington State, 2005-2014, Journal of Agromedicine, 24(2), 205-214.

Bureau of Labor Statistics 2004. Census of fatal occupational injuries. Washington, DC: U.S. Department of Labor, Bureau of Labor Statistics. [www.bls.gov/iif/oshwc/ cfoi/cfch0002.pdf].

Fosbroke, D. E., Kisner, S. M., Myers, J. R. 1997. Working lifetime risk of occupational fatal injury. American Journal of Industrial Medicine, 31(4), 459-467.

Garland, J., Belart, F., Crawford, R., Chung, W., Cushing, T., Fitzgerald, S., Green, P., Kincl, L., Leshchinsky, B., Morrissette, B., Sessions, J. and Wimer, J. 2019. Safety in steep slope logging operations, Journal of Agromedicine, 24(2), 138-145. 
Helmkamp, J.C., Bell, J.L., Lundstrom, W.J., et al. 2004. Assessing safety awareness and knowledge and behavioral change among West Virginia loggers. Injury Prevention; 10:233238.

Janocha, J. and Hopler C. 2018. The facts of the faller: Occupational injuries, illnesses, and fatalities to loggers 2006-2015; Beyond the Numbers: Workplace Injuries. U.S. Bureau of Labor Statistics, April 2018: 7(5) pp. 8 https://www.bls.gov/opub/btn/volume-7/the-facts-of-thefaller-occupational-injuries-illnesses-and-fatalities-to-loggers-2006-2015.htm

JMP®. 2015. Version Pro 14.0, SAS Institute Inc., Cary, NC, Copyright @2015.

Kaps, M.; Lamberson, W. R. 2004 Biostatistics for Animal Science; CABI Publishing is a division of CAB International: Wallingford, Oxfordshire.

McCulloch, C. (2003). Generalized Linear Mixed Models. NSF-CBMS Regional Conference Series in Probability and Statistics, Institute of Mathematical Statistics, 7 pp. 1 - 84.

Myers, J. R., Kisner, S. M, and Fosbroke, D. E. 1998. Lifetime risk of fatal occupational injuries within industries, by occupation, gender, and race. Human Ecol. Risk Assess. 4:12911307.

OSHA.2020.https://www.osha.gov/pls/imis/industry.search?p_logger=1\&sic=2411\&naic $\mathrm{s}=113310 \&$ State $=\mathrm{WV} \&$ officetype $=$ All\&Office $=$ All\&endmonth $=01 \&$ endday $=01 \&$ endyear $=2000$ $\&$ startmonth=12\&startday $=31 \&$ startyear=2018\&owner $=\&$ scope $=\&$ FedAgnCode $=$

Smith, D. W. 1999. Chainsaw Safety. Agri-life Extension Texas A\&M System. pp. 3 http://agsafety.tamu.edu/files/2011/06/CHAINSAW-SAFETY3.pdf 
Appendix

Safety Audit Form

52 I P g e 
WV Loggers SAFETY INITIATIVE - PERfoRMANCE MoNitoring INSPECTION

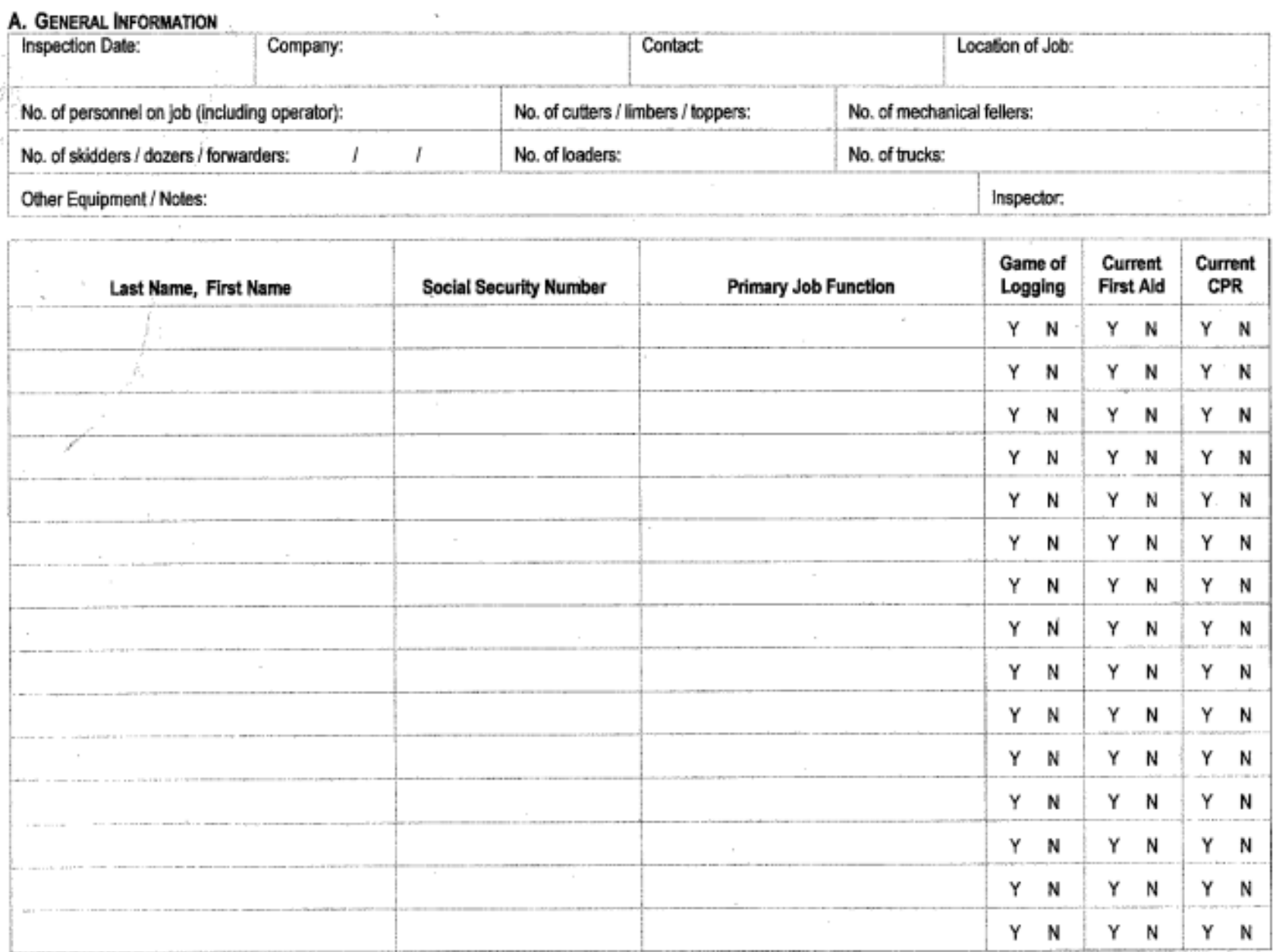

\section{B. OSHA COMPLIAMCE (FOR BASEUNE INSPECTIONS ONLY)}

\begin{tabular}{|c|c|}
\hline General Requirements & \\
\hline OSHA Form 200 ( 10 or more employees only) & $\mathrm{Y} \quad \mathrm{N}$ \\
\hline OSHA Poster & $\mathrm{Y} \quad \mathrm{N}$ \\
\hline \multicolumn{2}{|l|}{ Hazard Communication } \\
\hline Witten Program & $\mathrm{Y} \quad \mathrm{N}$ \\
\hline Chemical List & $\mathrm{Y} \quad \mathrm{N}$ \\
\hline Material Safety Data Sheets & $\mathrm{Y} \quad \mathrm{N}$ \\
\hline Periodic ${ }^{1}$ Training Records & $\mathrm{Y} \quad \mathrm{N}$ \\
\hline \multicolumn{2}{|l|}{ Control of Hazardous Energy (Lockout/Tagout) } \\
\hline Written Program & $\mathrm{Y} N$ \\
\hline Written Procedures / Equipment Audits & $\mathrm{Y} \quad \mathrm{N}$ \\
\hline Periodic' Training Records & $\mathrm{Y} \quad \mathrm{N}$ \\
\hline
\end{tabular}

White Copy - WVFA

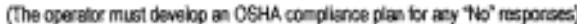

\begin{tabular}{|l|c|}
\hline Occupational Noise Exposure (Hearing Conservation) & \\
\hline Written Program & $\mathrm{Y} \mathrm{N}$ \\
\hline Audiometric Test Results & $\mathrm{Y} \mathrm{N}$ \\
\hline Annual Training Records & $\mathrm{N}$ \\
\hline Emergency Action / Fire Prevention Plan & $\mathrm{N}$ \\
\hline Emergency Telephone Numbers Listing & $\mathrm{N}$ \\
\hline Periodic' Training Records & $\mathrm{N}$ \\
\hline Logging Operations & $\mathrm{Y} \mathrm{N}$ \\
\hline Monthly Salety Meeting Records & $\mathrm{N}$ \\
\hline
\end{tabular}

${ }^{4}$ Peniodic is defined as a minimum of one training session for an OSHA standard

Pink Copy-WV Workers' Compensation

Bue Copy-Operator 


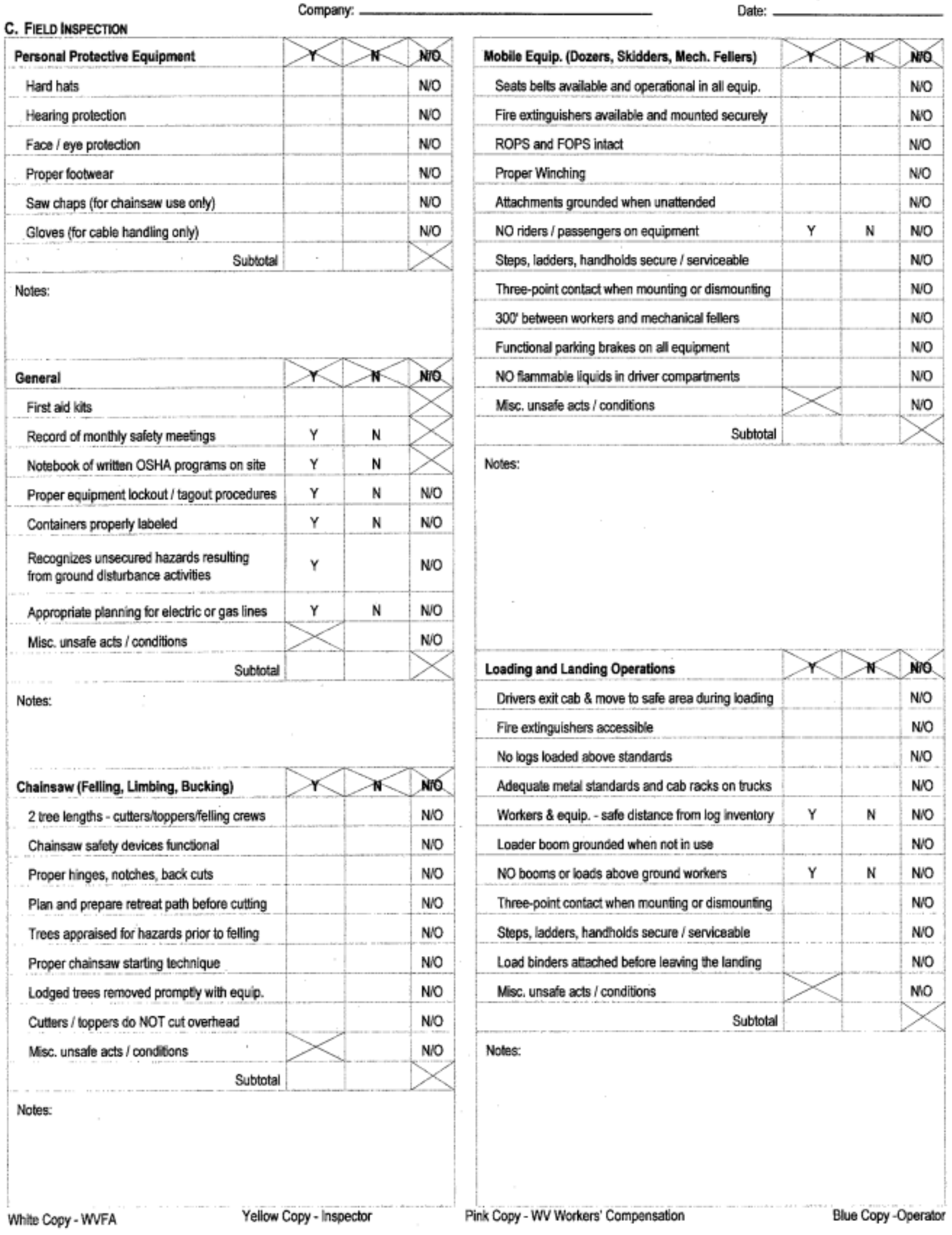




\section{SCORING}

Total available points for each category:
Company:

Date:

$\begin{array}{rr}\text { Personal Protective Equipment } & 30 \\ \text { General } & 10 \\ \text { Chainsaw (Felling, Limbing, Bucking) } & 30 \\ \text { Mobile Equipment (Dozers, Skidders, Mechanical Fellers) } & 15 \\ \text { Loading and Landing Operations } & 15 \\ \text { Total } & 100\end{array}$

Total points earned in each category are determined as:

1. Sum the number of both Yes and No responses on the Field Inspection form for each category and enter the totals in the Subtotal rows.

2. Determine the total number of observations for each category (Yes responses + No responses) and enter these numbers in Column A of the Scoring Summary Table.

3. Transfer the number of Yes responses for each category to the appropriate category in Column B of the Scoring Summary Table.

4. For each category, divide Column B by Column $\mathrm{A}$, round the result to the nearest 0.01 , and enter that number in Column C of the Scoring Summary Table.

5. For each category, multiply Column $\mathrm{C}$ by Column $\mathrm{D}$, round the result to the nearest 0.1 , and enter that number in Column $E$ of the Scoring Summary Table.

6. Sum the five subtotals in Column $E$ and enter this number into the Total Score box. If this total is 80 or higher, the company has received a passing score.

\begin{tabular}{l|c|c|c|c|c}
\multicolumn{1}{c|}{ Category } & $\begin{array}{c}\text { Total } \\
\text { Obs. } \\
\text { (A) }\end{array}$ & $\begin{array}{c}\text { Yes } \\
\text { (B) }\end{array}$ & $\begin{array}{c}\text { B/A } \\
\text { (C) }\end{array}$ & $\begin{array}{c}\text { Points } \\
\text { Avail. } \\
\text { [D] }\end{array}$ & $\begin{array}{c}\text { CXD } \\
\text { [E }\end{array}$ \\
\hline \hline Personal Protective Equipment & & & & 30 & \\
\hline General & & & & 10 & \\
\hline Chainsaw (Felling, Limbing, Bucking) & & & & 30 & \\
\hline Mobile Equipment & & & & 15 & \\
\hline Loading and Landing Operations & & & & 15 & \\
\hline
\end{tabular}

\section{E. COMMENTS}

The inspector may use this area to comment on problems noted during the inspection that do not appear on the inspection form, to elaborate on No responses, or to describe additonal salety efforts of the operator that are beyond the scope of this inspection.

\section{E. SIGNATURES}

Inspector Signature

Inspector Name

White Copy - WVFA
Yellow Copy - Inspector
Operabor or Representative Signature

Operator or Representative Name

Signature of the Operator or Representative verifies only that the inspection cccurred on the date indicated and does not necessarily indicate agreement with the results of the inspection. 